\title{
Reversible heat pump HVAC system with regenerative heat exchanger for electric vehicles: analysis of its impact on driving range
}

\author{
Sara Bellocchi ${ }^{\mathrm{a}}$, Giuseppe Leo Guizzi ${ }^{\mathrm{a}}$, Michele Manno ${ }^{\mathrm{a}, *}$, Marco Salvatori ${ }^{\mathrm{a}}$, \\ Alessandro Zaccagnini ${ }^{\mathrm{a}}$ \\ ${ }^{a}$ Dept. of Industrial Engineering, University of Rome Tor Vergata, Italy
}

\begin{abstract}
Besides providing energy for traction, an electric vehicle battery operates on-board auxiliary systems, among which air conditioning features the highest energy consumption and reduces significantly the driving range. Furthermore, electric vehicles heating needs are typically fulfilled through highconsuming resistors. In this respect, heat pumps promise higher energy efficiency and an increase in all-electric range.

This paper analyses a reversible heat pump HVAC system equipped with a regenerative heat exchanger for pre-conditioning and hygrometric comfort improvement, and assesses air-conditioning energy loads and their impact on driving range for a vehicle performing daily commutes in different Italian cities. The dynamic model was set up in a Modelica framework. The overall system integrates component models calibrated against experimental data.

Results confirm that air conditioning, consuming up to $32 \%$ of the energy required for traction on a daily commute, highly impacts on the all-electric range, which can decrease to $72 \mathrm{~km}$ from a base value of $94 \mathrm{~km}$. In heating mode, replacing a resistor with a heat pump reduces consumption by $17-$ $52 \%$ depending on geographical context, which proves to be highly effective in particularly demanding summer conditions lessening the driving range decrease up to $6 \%$.
\end{abstract}

Keywords: Automotive air conditioning, HVAC, Electric vehicles, Regenerative heat exchanger, Heat pump

\footnotetext{
${ }^{*}$ Corresponding author

Email address: michele.manno@uniroma2.it (Michele Manno)
} 


\section{Introduction}

Battery electric vehicles (EVs) are progressively emerging in the lightduty passenger market, featuring a stock of 740 thousands in 2015, 60 times more than in 2010 [1]. Remarkable efforts, under the joint support of governments and industry, have been directed towards EVs as a promising alternative to carbon intensive, polluting and oil dependent road transport. However, despite offering low environmental impact and noise pollution along with life-cycle cost savings and enhanced drivability, EVs large-scale adoption and diffusion is still limited by comparatively higher purchase costs and driving range restrictions [2-4].

On-board rechargeable batteries are the sole EVs power source, thus providing for both traction energy needs and auxiliary system requirements. Vehicle heating, ventilation and air-conditioning system (HVAC) features the highest energy consumption among all the accessory loads [5] and therefore may consume a substantial amount of the total energy stored. This results in a driving range reduction, further worsened by energy storage devices limited capacity. Previous studies have modeled the device-level function and energy consumption of HVAC systems as well as the impact on the vehicle driving range [6-11]. All these studies revealed a significant impact on driving range; depending on air-conditioner size, driving cycle and external weather conditions, the driving range decrease has been estimated in a range between $16 \%$ and $36 \%$ [6]. This calls for maximizing the efficiency of climate control systems to reduce energy consumption in both cooling and heating modes. Advanced glazing, recirculated air and cabin pre-conditioning have already been regarded as means of improving EVs conventional thermal control systems thus mitigating driving range reductions $[6,12,13]$.

Moreover, thermal comfort loads feature significant variations depending on external climate conditions. Thus, as the geographical context and time of day change, so does the air conditioning load and the driving range in turn. Although of key importance in affecting electric vehicles performance, previous studies estimated the air conditioning load disregarding hourly changes in weather variables, using for instance a daily-mean radiant temperature to describe a summer day for a given city [6] or two different temperatures for summer and winter conditions [14]. Only few studies assessed the dynamic variation of thermal loads as a function of location, season and time of the 
day to ultimately quantify the effect of geographical and temporal differences on the all-electric range $[13,15]$.

In particular, Kambly \& Bradley have carried out a research work aiming to quantitatively assess the extent to which the EV range is affected by cabin comfort conditioning loads and therefore by external weather conditions $[13$, 15]. EV range is shown to vary widely across the geography of the US throughout the time of day from a minimum of $95 \mathrm{~km}$ (for midday trips in hot and sunny ambient conditions) to a maximum of $128 \mathrm{~km}$ (for early morning trips in moderate ambient conditions). Commutes performed during the middle portion of the day, where temperatures and solar radiation are at their maximum values, feature the highest EV range reduction. Nevertheless, in this study the heating needs are fulfilled by means of a relatively inefficient resistance heater.

This solution is still typically adopted in EVs because of the lack of engine waste heat to recycle $[16,17]$. In particular, positive temperature coefficient (PTC) heaters are widely used by the industry in EV cabin heating in place of the engine coolant heater core of conventional vehicles [18-21]; however, these systems present limitations related to high costs and energy consumption [22].

However, in EVs climate control systems, heat pumps seem a more sustainable and efficient solution, so that heat pump (HP) systems are currently stepping into EVs market [23-25] as a reasonable solution. Several studies have been published demonstrating the feasibility of a reversible heat pump system for electric vehicle air conditioning, pointing to Coefficients of Performance (COP) slightly higher than 2 in heating mode and to electric driving range improvement over the use of PTC by $5-10 \%$ at low and mid ambient temperatures [26-33]. However, the dynamic performance of reversible heat pump systems with reference to hourly distributions of climate variables, geographical location and season has not been thoroughly evaluated in the literature, except for Neubauer \& Wood [32] who compared, among other things, heat pump systems to conventional PTC heaters.

In this paper, the impact of geographical context, season and time of day on cabin air conditioning energy needs is estimated for an electric vehicle commuting in different Italian cities. The HVAC system is based on a reversible heat pump, also equipped with a regenerative heat exchanger to further improve efficiency and hygrometric conditions both in cooling and heating operating modes. The performance of the proposed heat pump system is compared to that of a conventional PTC resistor to assess the corresponding energy savings in heating mode. The energy consumed for air 
conditioning and the resulting driving range reduction is dynamically evaluated for different commuting time options and locations throughout the year.

The model of the HVAC system is implemented in Dymola (Dynamic Modeling Laboratory), which provides a dynamic simulation environment to accurately model integrated and complex systems [34]. In particular, components from the Modelon Air Condition library [35] have been used and customized to build up the overall system model. Each component has been validated against experimental data provided by the original equipment manufacturer.

Results establish to what extent climatic variables, geographical location and time of travel affect the EV range, confirming that HVAC loads must necessarily be taken into account when estimating the actual driving range. The effectiveness of using a heat pump in place of PTC resistors and of the regenerative heat exchanger in improving both EV range and cabin comfort conditions has been assessed, evaluating under which climate conditions these systems prove to significantly increase the overall energy efficiency.

\section{Description of the HVAC system}

In this section the reversible heat pump system used in the model will be described. Reversible heat pump air conditioning systems work in A/C mode for cabin cooling and in heat pump mode for cabin heating, by means of a 4way valve that allows to reverse the refrigerant cycle. Figs. 1 and 2 represent the system schematic in cooling and heating mode respectively. A regenerative heat exchanger (ERV) has been also inserted for air preconditioning purposes.

\subsection{A/C operation}

\subsubsection{Air side}

In cooling mode, outside air needs to be dehumidified and cooled down to achieve cabin thermal comfort conditions. This is achieved through subsequent conditioning processes as following:

1. The proposed system inserts an Energy Recovery Ventilator (ERV), which is an air-to-air regenerative heat exchanger that allows the outside air flow to exchange both latent and sensible heat with air flowing from the cabin by means of a separating membrane. The incoming air 
mixture, interacting thermally with the recirculating flow, undergoes a pre-cooling and dehumidification process, before entering the internal heat exchanger, which acts as an evaporator in heating mode.

2. The air flows to the evaporator where it is further cooled down by exchanging heat with the refrigerant.

3. In mid-season cooling operation, the air exiting the evaporator may reach unacceptable low values (below $3^{\circ} \mathrm{C}$ ) and some reheating may be required before entering the cabin. In fact, despite working at the minimum speed, the compressor may still supply an excessive power when ambient temperature values are relatively cool (but not cold enough to provide for free cooling). Air reheating is achieved by means of an auxiliary internal heat exchanger that acts a condenser.

4. Having completed all the necessary conditioning treatments, air is ultimately blown into the cabin.

\subsubsection{Refrigerant side}

In cooling mode, the cabin thermal control system operates on a conventional vapor-compression refrigerating cycle. The internal heat exchanger acts as an evaporator in cooling mode, with the refrigerant absorbing heat from the air exiting the ERV. If the air exiting the evaporator needs to be reheated, the required refrigerant flow will be directed toward a heater, which, in turn, acts as a condenser allowing the working fluid to transfer heat to air entering the cabin. The external heat exchanger, located close to the electric motor and relatively far from the cabin, acts as a condenser in cooling mode, allowing the refrigerant to change its state by means of a thermal interaction with the outside air.

\subsection{Heating operation}

\subsubsection{Air side}

In heating mode (fig. 2), outside air needs to be humidified and heated up to meet cabin thermal comfort requirements. This is achieved through subsequent conditioning processes:

1. Fresh air from outside the vehicle goes to the ERV where it undergoes a pre-heating and humidification process exchanging with air flowing from the cabin, before entering the internal heat exchanger (condenser in heating mode). 
2. The air flows to the condenser where it is further heated up, exchanging heat with the refrigerant.

3. The air exiting the condenser undergoes a reheating process passing through the auxiliary condenser.

4. Having completed all the necessary conditioning treatments, air is ultimately blown into the cabin.

\subsubsection{Refrigerant side}

In heating mode, the cabin thermal control system operates on a heat pump continuous cycle so as to heat the incoming outside air up to comfort conditions. The refrigerant undergoes the same processes as those previously described for the refrigerating cycle, differing however in the roles of the internal and external heat exchangers. The internal heat exchanger now acts as a condenser, allowing heat to be transferred from the refrigerant to the air exiting the ERV. The external heat exchanger works instead as an evaporator, allowing the refrigerant to change its state by means of a thermal interaction with the outside air. The refrigerant flow is controlled by means of two fourway valves, as illustrated in Figs. 1 and 2 (the valves are located next to the compressor and the expansion valve), which allow to switch between cooling and heating mode.

\section{Numerical model description}

\subsection{HVAC components}

The proposed system has been modeled and simulated in a Modelica/ Dymola framework. The model has been calibrated with reference to standard industry components, using Modelon Air Conditioning library features [35].

\subsubsection{Media}

Modelon Air Conditioning library provides specific components to model the fluids involved in the physical processes: refrigerant and outside air.

The refrigerant fluid undergoing the thermodynamic cycle is R134a. The choice of not taking into account any possible replacement for this fluid, despite the ban gradually introduced by European Union's f-gas regulations (Regulation (EC) No 842/2006 and Directive 2006/40/EC), is justified by the necessity to compare the results obtained with existing literature and experimental data for model validation. Besides, under similar cooling capacity, 
it has been demonstrated that the COPs of HVAC systems using R134a or R1234yf as working fluids are comparable [36, 37].

The refrigerant R134a is modeled with reference to Helmholtz equation from Span [38] and valid within a specific range of temperature and pressure, precisely going from $-103{ }^{\circ} \mathrm{C}$ to $102{ }^{\circ} \mathrm{C}$ and $0.39 \mathrm{kPa}$ to $70 \mathrm{MPa}$.

Air has been represented by means of the Modelon humid air model, valid within 0 to $150^{\circ} \mathrm{C}$. Sources and sinks components are available in the library to allow specific fluid parameters to be controlled. As for the air entering the system, flow rate, temperature and relative humidity have been set. Air temperature and relative humidity reflect the actual external weather conditions throughout the year, made available by the Meteorological Service of Aeronautica Militare [39] for different Italian cities.

\subsubsection{Compressor}

Electrically-driven compressors are typically employed in EV cabin thermal control systems in place of mechanical compressors. These components are directly powered by a brushless electric motor controlled by an inverter to allow variable speed operations $[40,41]$. In the proposed model, a MASTERFLUX Sierra03-0982Y3 compressor [42] has been used as a reference in terms of operating parameters and efficiencies.

The compressor has been modeled using the fixed displacement component available in Modelon Air Conditioning library, which requires, as input parameters, the compressor effective volumetric and isentropic efficiency.

Compressor performance depends on pressure ratio, compressor speed and relative displacement. The minimum and maximum rotational speed have been set respectively to 1800 and $6500 \mathrm{rpm}$. Compressor efficiencies are defined via three tables that use pressure ratio and rotational speed as inputs. Operating performance has been assessed with reference to the Masterflux data sheet for a $48 \mathrm{~V}$ compressor [42]. The polynomial function therein suggested has been used to estimate flow rate and power consumption, evaluated as function of compressor speed and refrigerant temperature at the suction and discharge sides.

\subsubsection{Evaporator}

In cooling mode, the internal heat exchanger, physically located by the nozzles through which air enters the cabin, acts as an evaporator thus ensuring the refrigerant change of state from liquid to slightly superheated vapor. In heating mode, instead, it is the external heat exchanger, located in the 
electric motor proximity and relatively far from the passenger cabin, that acts as an evaporator.

The evaporator is a flat plate type and has been modeled in Dymola using the available plate evaporator component provided in the Air Conditioning library. This model for a compact automotive evaporator is based on a microtube heat exchanger type for vertical refrigerant flow, which in general allows heat transfer and refrigerant flow to change their direction. The component provides accurate equations to model heat exchange [43, 44] and pressure drops [45, 46].

\subsubsection{Condenser}

In heating mode, the internal heat exchanger located in the proximity of the nozzles acts a condenser thus ensuring the refrigerant change of state from superheated vapor to liquid. In cooling mode, instead, it is the external heat exchanger that acts as a condenser. The condenser is a horizontal microtubes type and has been modeled in Dymola using the condenser component available in the Air Conditioning library.

The same equations as in the evaporator component are used to model heat exchange and pressure drops.

\subsubsection{Expansion Valve}

The thermostatic expansion valve ensures the refrigerant to undergo a pressure drop through an isenthalpic expansion process. An electronicallyregulated orifice controls the refrigerant flow rate by means of a temperature sensor, ensuring the desired superheat temperature difference at the compressor suction side [47].

\subsubsection{Energy Recovery Ventilator (ERV)}

Energy Recovery Ventilators are typically used in building air conditioning systems for thermal comfort control [48, 49], but these components are progressively being evaluated for application in the automotive industry $[50,51]$.

In the proposed system, the ERV is based on two polymeric membranes, which allow both latent and sensible heat exchange between the two circulating fluids. Heat and mass (in the form of water molecules) are transferred, while the passage of other molecules (such as carbon dioxide) is inhibited. Contrary to a conventional heat exchanger, ERV selectivity allows the latent 
heat to be transferred thus achieving potential advantages in terms of energy savings related to air conditioning processes.

Outside air goes into the ERV where it interacts with air flowing from the cabin. Latent and sensible heat are exchanged through the selective membrane, resulting in an overall enhancement of air conditions.

A model of ERV has been created and implemented in Modelica with reference to a $45 \times 20 \times 30 \mathrm{~cm}$ industrial component [52], not specifically developed for an automotive application. The amount of space taken could be substantially reduced by decreasing the width of air flow passage, at the price of a slight increase in pressure drops. Latent and sensible heat exchange efficiency can be described as follows:

$$
\begin{gathered}
\eta_{s}=\frac{T_{\text {out }}^{(1)}-T_{(\text {in })}^{(1)}}{T_{\text {out }}^{(2)}-T_{\text {in }}^{(1)}} \\
\eta_{l}=\frac{\omega_{\text {out }}^{(1)}-\omega_{(\text {in })}^{(1)}}{\omega_{\text {out }}^{(2)}-\omega_{\text {in }}^{(1)}}
\end{gathered}
$$

where:

- $T_{\text {in }}^{(1)}, \omega_{\text {in }}^{(1)}, T_{\text {out }}^{(1)}$ and $\omega_{\text {out }}^{(1)}$ are temperature and absolute humidity of outside air entering and exiting the ERV;

- $T_{\text {out }}^{(2)}$ and $\omega_{\text {out }}^{(2)}$ are temperature and absolute humidity of the cabin air flow exiting the ERV.

ERV efficiencies (as shown in Fig. 3) were provided by the manufacturer [52] as functions of air flow rate and implemented in the model to characterize precisely the heat exchanger performance.

\subsubsection{Model validation}

The proposed air-conditioning system has been modeled using Modelon Air Conditioning library, which features state-of-the-art air-conditioning models specifically created with reference to automotive applications. This library is a proven tool for air conditioning system design and virtual prototyping in the automotive sector, as demonstrated by its wide adoption in design, analysis and optimization of on-board air conditioning systems $[5,35]$.

Furthermore, the library provides several ways to calibrate and validate design options and component settings. In this study, each component used 
to model the HP system has been validated with reference to experimental data provided by the equipment manufacturer: FIAT research center in the case of heat exchangers (evaporator, condenser, heater core), and the companies already mentioned in the corresponding preceding sections in the case of compressor and ERV.

The accuracy of the model has thus been ensured by means of validation against experimental data. By way of example, Fig. 4 reports the condenser heat flux as a function of air flow rate over the entire operating range, showing a good fit between model and available data, with a maximum discrepancy of $6 \%$, well within the acceptable range and the experimental data uncertainty.

\subsection{Thermal loads}

Heating and cooling thermal loads are essential to assess HVAC power requirements and energy consumption and consist of the following contributions:

- radiation load;

- environmental load;

- metabolic load;

- ventilation load.

A specific component has been created in Modelica to model thermal loads within the cabin as function of geographical location and time of travel by implementing the necessary heat exchange and heat balance equations [53].

\subsubsection{Radiation load}

The thermal load due to the effect of solar radiation can be divided into direct and diffuse components, leading to the following fluxes:

$$
\begin{gathered}
\dot{Q}_{d i r}=\sum_{\text {surfaces }} S \dot{I}_{d i r} \cos \zeta \\
\dot{Q}_{d i f}=\sum_{\text {surfaces }} S \dot{I}_{d i f}
\end{gathered}
$$


where $S$ is the surface considered, $I_{d i r}$ and $I_{d i f}$ are respectively the direct and diffuse radiation acting on the surface and $\zeta$ is the angle between sun's rays and the line normal to the surface.

The amount of incident solar power depends on a number of factors:

- solar radiation geometry, which is based on solar angles, evaluated as function of location/latitude, season/time of year and time of day;

- local climate variables;

- inclination of the collecting surface in the direction of the sun.

The amount of solar energy is thus highly affected by the particular geographical context, time of travel and relative geometry between vehicle surfaces and sun rays. In order to estimate accurately energy requirements for cabin comfort needs, a dynamic variation of climatic variables during the day and throughout the year has been implemented in the model. Dry bulb temperature and relative humidity values have been made available by the Meteorological Service of Aeronautica Militare [39] for different Italian cities and, for each month of the year, an average daily trend has been estimated.

Figs. 5 and 6 represent Rome average days in terms of air temperature $(5 \mathrm{a}, 6 \mathrm{a})$ and relative humidity $(5 \mathrm{~b}, 6 \mathrm{~b})$ for winter and summer months respectively. This procedure has been repeated for climate data belonging to different Italian cities, specifically Rome, Turin, Milan, Bologna, Bari and Naples. Temperature and relative humidity are compared in Figs. 7 and 8 for the different cities analyzed with regard to a typical winter and summer month daily trend.

According to the Mediterranean Italian climate, cabin heating might be required in some spring days and cooling might still be necessary in the beginning of autumn, generally during seasonal transition periods. Hence, April and October have been included in both summer and winter months potentially entailing the cabin control system to work either in heating or cooling mode depending on the particular weather conditions.

The relative inclination between vehicle surfaces and sun's rays has been randomized and the latitude varied according to the city analyzed.

Given that the amount of direct radiation varies depending on cloudiness, for each month of the year the number of overcast and sunny days has been taken into account. The radiation load representative of the average day has been derived as a weighted average between these two conditions over the entire month. 


\subsubsection{Ambient load}

Environmental conditions highly affect the thermal load acting on the vehicle. The heat flux exchanged between vehicle and environment can be expressed as:

$$
\dot{Q}_{a m b}=\sum_{\text {surfaces }} S U\left(T_{a m b}-T_{\text {int }}\right)
$$

where the global heat exchange coefficient includes convection and conduction heat transfer coefficients:

$$
U=\left(\frac{1}{h_{e}}+\frac{\lambda}{k}+\frac{1}{h_{i}}\right)^{-1}
$$

In particular, the external convective heat transfer coefficient $h_{e}$ has been empirically modeled and calibrated with reference to cabin temperature as provided in [13]. This results in the following relation, where $h_{e}$ is in $\mathrm{W} /\left(\mathrm{m}^{2} \mathrm{~K}\right)$ and $v$ in $\mathrm{m} / \mathrm{s}$ :

$$
h_{e}=8.68+6.64 \sqrt{v}
$$

\subsubsection{Metabolic load}

Passengers and driver metabolism generates a thermal load quantifiable as a function of the number of occupants, their height and weight, including a coefficient representing their metabolic activity, as follows [53]:

$$
\dot{Q}_{m e t}=\sum_{\text {passengers }} M A_{b o d y}
$$

where $M$ is a metabolic factor equal to $85 \mathrm{~W} / \mathrm{m}^{2}$ and $55 \mathrm{~W} / \mathrm{m}^{2}$ for driver and passengers respectively, while $A_{b o d y}$ is an estimate value for the body surface dependent on passengers height and weight.

In the proposed model, the cabin is occupied by the driver only; the passengers metabolic loads are disregarded as a result.

\subsubsection{Ventilation load}

Fresh air requirements within a cabin recommend a certain air change rate to keep carbon dioxide level, generated by passengers' metabolism, under a certain level [54]. The corresponding heat flux can be expressed as follows:

$$
\dot{Q}_{v e n t}=\dot{m}_{v e n t}\left(h_{e x t}-h_{\text {int }}\right)
$$




\subsection{Vehicle cabin}

The cabin has been characterized in terms of geometry and physical properties separately for each surface making up the cabin: windows, doors, roof, floor, boot, firewall and windscreen. Data refer to the FIAT Panda model and have been provided by FIAT Research Center.

\subsubsection{Geometry}

The vehicle cabin has been modeled with reference to a generic light-duty passenger car features. The different surfaces making up the vehicle exterior have been modeled considering their relative inclination and area thus allowing a reliable and accurate estimation of radiation and environmental loads.

\subsubsection{Physical properties}

Surfaces physical properties have been included in the thermal model in terms of absorption, transmissivity, convection and conduction coefficients and thickness.

\subsubsection{Cabin validation}

The cabin behavior has been verified by running the model assuming the vehicle parked outdoor and subject to the radiation load with the HVAC turned off, and comparing the obtained internal temperature values with results available in literature. In particular, the system has been simulated under the same climate conditions as those used by Kambly \& Bradley [13], and the comparable response in terms of interior temperature daily profile proves the model validity.

\subsection{Driving cycle}

The driving cycle selected for the analysis is the Worldwide harmonized Light vehicles Test Cycle (WLTC) implemented in the first global standard procedure for determining the levels of pollutants and $\mathrm{CO}_{2}$ emissions, fuel or energy consumption, and electric range from light-duty vehicles [55]. The cycle total distance is $23.26 \mathrm{~km}$ featuring a duration of $1800 \mathrm{~s}$ and an average speed equal to $46.5 \mathrm{~km} / \mathrm{h}$. The cycle is made up of four speed zones: one representative of urban driving, one suburban driving, one extra-urban driving, and a highway zone. 
The driving cycle well represents the average distance for daily commutes in Italy for people who have to partially drive on highway to get to work [56]; in fact, if repeated twice per day, it covers a total distance of $46.52 \mathrm{~km}$.

For a typical light-duty passenger vehicle, the electric energy required to perform a WLTC cycle has been estimated as approximately $17 \mathrm{kWh} / 100 \mathrm{~km}$ [57], in line with other values reported in literature [14, 58-60]. With reference to a battery capacity of $16 \mathrm{kWh}$ [61], the resulting driving range will be equal to $94 \mathrm{~km}$, if only energy for traction is taken into account and the battery fully discharged. However, range values can significantly decrease when HVAC consumption is considered.

\section{Results and discussion}

\subsection{Model setup}

The model assesses the cabin thermal comfort energy demand as a function of day and time of the year, for a vehicle performing daily commutes in different Italian cities. Fig. 9 represents a schematic of the model including the system components as previously described.

The simulation requires the following input variables that can be chosen at user's will to represent a particular geographical context and vehicle utilisation mode:

- day and month of the year;

- duration of travel;

- driving cycle;

- trip start time;

- city, characterised in terms of:

- outside temperature;

- outside relative humidity;

- latitude.

The model provides results in terms of HVAC performance: it monitors and controls temperature, and calculates the electric power consumption by the compressor and HVAC auxiliary components such as fans, the overall 
COP, and so on. A PID controller is employed to regulate the compressor speed so as to maintain cabin comfort conditions, specifically set to 22 and $24^{\circ} \mathrm{C}$ respectively in heating and cooling mode.

In order to estimate potential ERV savings with respect to traditional heat-pump HVAC systems, two other similar models have been also implemented in Dymola, representing respectively:

- a heat-pump HVAC system without air recirculation and ERV. This model will be identified as the base case scenario, where air is continually drawn into the internal heat exchanger from the outside without being preprocessed;

- a heat-pump HVAC system with air recirculation and without ERV. This model entails a fixed air flow from the outside equal to $0.04 \mathrm{~kg} / \mathrm{s}$ as to guarantee sufficient air renewal (for 4 passengers approximately) and a remaining recirculating air flow varying depending on power requirements. As a result, the recirculating air flow ranges from a minimum of 0 to a maximum of $60 \%$ of the total air flow rate.

Models have been first tested with reference to Rome average climatic conditions; results have been analysed and compared for the above-mentioned different case scenarios.

\subsection{Seasonal and temporal effects on HVAC energy consumption}

Testing the basic HVAC system model (i.e. without air recirculation and ERV) on the most demanding condition (i.e. July at 13:00), a displacement of $35 \mathrm{~cm}^{3}$ proves to be adequate to fulfill thermal comfort requirements. However, the adoption of an ERV or a recirculation system allows to achieve cabin thermal comfort by employing a significantly smaller compressor $\left(24 \mathrm{~cm}^{3}\right)$.

The energy required for cabin cooling and heating has been estimated and shown in Figs. 10 and 11 by simulating a basic heat-pump HVAC system model without air recirculation and ERV. The energy required for HVAC is divided into compressor and ventilation consumption, expressed as a percentage of the energy for traction and evaluated for three different times of travel, i.e. 8:00, 13:00, 18:00, and month of the year.

In summertime, commuting performed during midday hours feature the highest energy consumption, with a peak of $38 \%$, with a significant increase in July and August as compared to the other summer months. Travels performed at 8:00 and 18:00 show comparable values in terms of HVAC energy 
requirements which are always below $30 \%$ of the energy required for traction and slightly higher for evening commuting. HVAC energy can be neglected for April regardless of the time of travel.

As for winter months, the highest amount of energy for cabin thermal control is required at 8:00, although evening travels are comparable in terms of energy consumption. Precisely, the most demanding months are January, February and December requiring approximately $16 \%$ of traction energy for cabin heating. HVAC energy can be neglected for April regardless of the time of travel being lower than $3 \%$ in any case.

Overall, the energy required for air conditioning represents a significant load to be fulfilled, featuring a significant variation during the day and the year depending on external weather conditions. Particularly, on average it ranges from $5 \%$ to $35 \%$ in summer and from $3 \%$ to $16 \%$ in winter. Summer loads may be more than twice than winter ones when peak conditions are compared (i.e. December in winter and July in summer). Season transition periods (i.e. April and October) show the smallest energy loads for cabin thermal control; in fact, most of the time free heating or cooling proves to be enough to cater for HVAC needs. Fan consumption is always a negligible percentage of the total HVAC energy.

\subsection{ERV performance}

HVAC energy consumption has been assessed for each model and Fig. 12 compares compressor electric power requirements for the three simulated scenarios (i.e. base, air recirculation and ERV) for a travel performed in July at 13:00.

For HVAC systems employing an ERV or an air recirculation system, power consumption is significantly lower than the base case on summer peak conditions. This results in an energy reduction to achieve thermal comfort needs and, therefore, in an increased driving range. In this respect, Fig. 13 displays the ratio $E_{H V A C} / E_{\text {trac }}$ and the driving range with reference to the theoretical range when HVAC consumption is not taken into account, i.e. $94 \mathrm{~km}$, over the entire day for the three models.

Pre-cooling through either the regenerative heat exchanger and the air recirculation brings about similar advantages in terms of HVAC energy consumption allowing a reduction of up to $14 \%$ of HVAC energy expressed as a percentage of the energy required for traction, with corresponding benefits on the driving range. However, an ERV-equipped HVAC system allows additional advantages in terms of hygrometric comfort by regulating cabin 
air humidity besides its temperature and guaranteeing a continuous supply of fresh air. For this reason, an ERV system has been identified as the most suitable solution to improve efficiency and comfort.

It is worth mentioning that both the ERV and the recirculation system start operating only when the cabin temperature becomes lower than outside temperature, thus the initial transient period to bring the cabin temperature to comfort levels is automatically excluded. This results in both ERV and recirculation functioning only for $60 \%$ of the total travel time, that in our simulation is $30 \mathrm{~min}$. If the duration of the travel increased, pre-cooling/ recirculation benefits would increase in turn.

HVAC energy savings have been estimated for the same travel times as above and shown in Fig. 14 only for the ERV model, given that both ERV and air recirculation provide very similar results. The ERV proves to be highly effective in particularly demanding weather conditions, i.e. July and August at 13:00 travel time, saving up to $13 \%$ of the total energy required for both traction and air-conditioning as compared to HVAC consumption for the base case scenario. This results in a corresponding increase of the driving range. However, when outside temperatures are relatively cooler, the use of ERV does not bring about advantages in terms of energy savings, at least for the Italian type of climate.

\subsection{HVAC energy consumption: impact of geographical location}

A similar analysis has been carried out for winter months and extended to other Italian cities. Values of the ratio $E_{H V A C} / E_{\text {trac }}$ and the resulting driving range, for both summer and winter seasons, have been assessed considering two different commutes with the outward travel occurring in both cases at 8:00 and two different return travel times respectively at 13:00 and 18:00. Outward and return travels feature the same duration and follow the WLTC driving cycle. Results are summarized in Figs. 15-18 in terms of seasonal distribution of HVAC energy consumption and driving range for summer and winter and for both commuting options. The boxplots show the minimum, first quartile, median and mean, third quartile, and maximum values for HVAC energy over the season analysed. Results are compared between the base and the ERV-equipped HVAC system.

In summer, daily commutes including an evening travel are advantageous in terms of HVAC energy consumption and obviously Southern Italy proves to more affected by external weather conditions than the North. With reference to the base case scenario, this results in Bari featuring the highest 
energy needs for cabin cooling, with a maximum of $32 \%$ of the energy for traction and an average $E_{H V A C} / E_{\text {trac }}$ equal to $15 \%$ and $12.5 \%$ for return travels occurring respectively at 13:00 and 18:00. The driving range proves to be highly affected by the air-conditioning energy needs and can be reduced down to $72 \mathrm{~km}$ in the worst case. Turin here shows the lowest HVAC loads with an average value of $10 \%$ and $8 \%$ of the energy required for traction for return travels at 13:00 and 18:00. As compared to the base case, using an ERV-equipped air-conditioning system, the driving range reduction can be decreased up to approximately $6 \%$ and, on average, by $3 \%$.

In winter, commutes including an evening return travel obviously require higher HVAC energy loads than return travels at 13:00. Among the different Italian cities analysed, Turin shows the highest HVAC energy consumption with $E_{H V A C} / E_{\text {trac }}$ a maximum of $20 \%$ and average values equal to $10 \%$ and $13 \%$ for return travels occurring respectively at 13:00 and 18:00 employing a base HVAC system. As a consequence, the driving range can be reduced down to $79 \mathrm{~km}$. On the other hand, Naples features the lowest energy consumption for cabin comfort needs, precisely 5 and $7.5 \%$ of the energy required for traction for return travels at 13:00 and 18:00. Results reflect the difference in weather variables between Northern and Southern Italy. An ERV-equipped air-conditioning system allows to decrease the driving range reduction up to approximately $4 \%$ and, on average, by $2 \%$.

\subsection{Estimate of HVAC annual energy consumption}

Finally, the benefits of the adoption of an ERV-equipped system in terms of energy savings over the entire year have been quantified considering 20 daily commutes per month. Results are summarized in Fig. 19.

HVAC energy requirements assessed over the entire year for the different Italian cities reveal that the energy required for cabin thermal control is in the range $200-250 \mathrm{kWh}$, i.e. $10-13 \%$ of traction energy. Moreover, the difference between North and South Italy appears to be levelled out once the whole year is taken into account. The adoption of a HVAC system employing a regenerative heat exchanger reduces energy consumption by $20-25 \%$.

In wintertime, the advantages of employing a heat pump-based system over conventional PTC resistors can be quickly assessed through its COP. Fig. 20 show average COP values in winter operating conditions. It is worth mentioning that COP is penalized by relatively long transients compared to the actual travel time of $30 \mathrm{~min}$ only. COP in winter ranges between 1.2 and 1.9 for a basic heat pump-based HVAC system and from 1.3 to 2.1 
for an analogous system equipped with an ERV. The cabin thermal power requirement being equal, this results in energy savings ranging between 17 and $52 \%$ when conventional PTC resistors are substituted with a heat pumpbased HVAC system.

\section{Conclusions}

This study assesses how location, season and time of the day affect HVAC loads and driving range of an electric vehicle performing daily commutes in different Italian cities. A reversible heat pump air-conditioning system equipped with a regenerative heat exchanger (ERV) has been modeled and the energy consumed for air conditioning purposes dynamically evaluated for different commuting times and locations throughout the year. The outcomes of this model have been compared with those of two other models representing respectively a basic heat pump HVAC system and a heat pump HVAC system employing a variable recirculating air flow.

Results confirm that cabin air-conditioning consumes a significant amount of power and therefore must be taken into account when estimating the actual driving range. HVAC loads have been assessed throughout the year for the basic HVAC system in the first place, showing that energy consumed for EV air-conditioning purposes can be as high as $38 \%$ of the energy required for traction, highly affecting the driving range that can reduce from $94 \mathrm{~km}$, when air-conditioning loads are not taken into account, down to $68 \mathrm{~km}$ in the most demanding summer conditions. Both time and location of commute affect substantially the energy consumption.

The adoption of a regenerative heat exchanger proves to be effective from an energy efficiency perspective, lessening the driving range reduction by $2-$ $6 \%$, a figure that can increase with the duration of the travel. Therefore, a heat pump-based HVAC system provided with an ERV allows significant energy savings, comparable to what could be achieved with air recirculation, along with a full cabin air renewal as an additional benefit, while taking a reasonably small amount of space.

In heating mode, the average effectiveness of heat pump systems used in place of PTC resistors for cabin heating brings about energy savings in the range $17-52 \%$ depending on the geographical context and on the employment of an ERV-equipped system.

Overall, HVAC energy requirements assessed over the entire year for the different Italian cities reveal that the energy required for EVs thermal comfort 
needs is in the range $200-250 \mathrm{kWh}$, i.e. $10-13 \%$ of traction energy, proving to be a significant parameter to be considered when evaluating the actual driving range of an electric vehicle.

\section{Acknowledgements}

This work was supported by the Italian Ministry for Development in the framework of "Industria 2015 Bando Nuove Tecnologie per la mobilità sostenibile", project n. MS01_00011 "MECCANO".

The authors would also like to acknowledge the invaluable effort provided by all undergraduate students that worked on the project: Elisa Capuano, Simone Noce, Francesco Sabatini and Leonardo Santaroni, as well as the contribution of Meteorological Service of Aeronautica Militare, for having provided climatic data.

\section{References}

[1] Cazzola P, Gorner M, Teter J, Yi W. Global EV Outlook 2016. Tech. Rep.; International Energy Agency; 2016. URL: https://www.iea.org/publications/freepublications/ publication/global-ev-outlook-2016.html.

[2] Hawkins TR, Singh B, Majeau-Bettez G, Strømman AH. Comparative Environmental Life Cycle Assessment of Conventional and Electric Vehicles. J Ind Ecol 2013;17(1):53-64. doi:10.1111/j.1530-9290.2012. 00532.x.

[3] Michalek JJ, Chester M, Jaramillo P, Samaras C, Shiau CSN, Lave LB. Valuation of plug-in vehicle life-cycle air emissions and oil displacement benefits. Proc Natl Acad Sci USA 2011;108(40):16554-8. doi:10.1073/ pnas. 1104473108.

[4] Duvall M. Advanced Batteries for Electric-Drive Vehicles A Technology and Cost-Effectiveness Assessment for Battery Electric Vehicles, Power Assist Hybrid Electric Vehicles, and Plug-In Hybrid Electric Vehicles. Tech. Rep.; Electric Power Research Institute; 2016. URL: http://www.epri.com/abstracts/Pages/ ProductAbstract . aspx?Product Id=000000000001009299. 
[5] Shojaei S, Robinson S, Chatham C, McGordon A, Marco J. Modelling the Electric Air Conditioning System in a Commercially Available Vehicle for Energy Management Optimisation. In: SAE Technical Paper. SAE International; 2015,doi:10.4271/2015-01-0331.

[6] Farrington R, Rugh J. Impact of Vehicle Air-Conditioning on Fuel Economy, Tailpipe Emissions, and Electric Vehicle Range. Tech. Rep.; National Renewable Energy Laboratory; 2000. URL: http://www.nrel. gov/docs/fy00osti/28960.pdf.

[7] Hendricks TJ. Vehicle Transient Air Conditioning Analysis: Model Development \& System Optimization Investigations. Tech. Rep.; National Renewable Energy Laboratory; 2001. URL: http://www.nrel. gov/docs/fy01osti/30715.pdf.

[8] Rugh J. Integrated numerical modeling process for evaluating automobile climate control systems. In: SAE Technical Paper. SAE International; 2002,doi:10.4271/2002-01-1956.

[9] Johnson VH. Fuel used for vehicle air conditioning: a state-by-state thermal comfort-based approach. In: SAE Technical Paper. SAE International; 2002,doi:10.4271/2002-01-1957.

[10] Torregrosa B, Payá J, Corberán J. Modelling of mobile air conditioning systems for electric vehicles. In: $4^{\text {th }}$ European Workshop on Mobile Air Conditioning and Vehicle Thermal Systems. Turin; 2011,.

[11] Lee JT, Kwon S, Lim Y, Chon MS, Kim D. Effect of Air-Conditioning on Driving Range of Electric Vehicle for Various Driving Modes. In: SAE Technical Paper. SAE International; 2013,doi:10.4271/2013-01-0040.

[12] Barnitt RA, Brooker AD, Ramroth L, Rugh J, Smith KA. Analysis of Off-Board Powered Thermal Preconditioning in Electric Drive Vehicles. In: 25th World Batter. Hybrid Fuel Cell Electr. Shenzhen, China; 2010,URL: www.nrel.gov/docs/fy11osti/49252.pdf.

[13] Kambly K, Bradley TH. Geographical and temporal differences in electric vehicle range due to cabin conditioning energy consumption. J Power Sources 2015;275:468-75. doi:10.1016/j.jpowsour.2014.10.142. 
[14] Gennaro MD, Paffumi E, Martini G, Manfredi U, Scholz H, Lacher H, et al. Experimental investigation of the energy efficiency of an electric vehicle in different driving conditions. In: SAE Technical Paper. SAE International; 2014,doi:10.4271/2014-01-1817.

[15] Kambly KR, Bradley TH. Estimating the HVAC energy consumption of plug-in electric vehicles. Journal of Power Sources 2014;259:117-24. doi:10.1016/j.jpowsour.2014.02.033.

[16] Zhang J. Structural features of fully electric air conditioning system. Automob Maint 2006;12:4-5.

[17] Guyonvarch G, Aloup C, Petitjean C, de Monts de Savasse A. 42V Electric Air Conditioning Systems (E-A/CS) for Low Emissions, Architecture, Comfort and Safety of Next Generation Vehicles. SAE Technical Paper 2001;doi:10.4271/2001-01-2500.

[18] Umezu K, Noyama H. Air-Conditioning system For Electric Vehicles (i-MiEV). In: SAE Automotive Alternate Refrigerant Systems Symposium. 2010,URL: http: //www. sae.org/events/aars/presentations/ 2010/W2.pdf.

[19] 2015 Smart Electric Drive Manual. 2014. URL: https: //www.smart. com/content/dam/smart/CA/pdf/2015_smart_ electric_drive_manual6522008013_FINAL.pdf.

[20] Life Cycle Environmental Certificate Mercedes-Benz B-Class Electric Drive. 2014. URL: https://www.daimler.com/images/ sustainability/produkt/new-enviromentalcertificates/ daimler-umweltzertifikat-mb-b-klasse-electric-drive.pdf.

[21] Meyer J. Advanced Climate Systems for EV Extended Range (ACSforEVER). In: DoE Vehicle Technologies Office Merit Review 2015. Halla Visteon Climate Control Corp.; 2015,URL: https : //energy .gov/ sites/prod/files/2015/07/f24/vss135_meyer_2015_o.pdf.

[22] Qi Z. Advances on air conditioning and heat pump system in electric vehicles - A review. Renew Sustain Energy Rev 2014;38:754-64. doi:10. 1016/j.rser.2014.07.038. 
[23] Nissan LEAF Heat-Pump Cabin Heater. 2014. URL: http://www.nissan-global. com/EN/TECHNOLOGY/OVERVIEW/heat_ pump_cabin_heater.html.

[24] The e-Golf Product Guide. 2016. URL: http://www.volkswagen. ie/content/medialib/vwd4/ie/pdf-downloads/product-guides/ e-golf-product-guide/_jcr_content/renditions/rendition. download_attachment.file/161005_ek_e-golf_october-2016.pdf.

[25] The heat pump or how to optimize Zoe's range. 2015. URL: https://group.renault.com/en/passion-2/innovation/ renault-a-born-innovator/heat-pump/.

[26] Suzuki T, Ishii K. Air Conditioning System for Electric Vehicle. In: SAE Technical Paper. SAE International; 1996,doi:10.4271/960688.

[27] Meyer J, Yang G, Papoulis E. R134a Heat Pump for Improved Passenger Comfort 2004;doi:10.4271/2004-01-1379.

[28] Pommé V. Reversible Heat Pump System for an Electrical Vehicle. In: SAE Technical Paper. SAE International; 1997,doi:10.4271/971772.

[29] Kowsky C, Wolfe E, Leitzel L, Oddi F. Unitary HPAC System. SAE Int J Passeng Cars - Mech Syst 2012;5(2):1016-25. doi:10.4271/ 2012-01-1050.

[30] Hosoz M, Direk M. Performance evaluation of an integrated automotive air conditioning and heat pump system. Energy Conversion and Management 2006;47(5):545-59. doi:10.1016/j . enconman.2005.05.004.

[31] Yokoyama A, Osaka T, Imanishi Y, sekiya S. Thermal management system for electric vehicles. SAE Int J Mater Manuf 2011;4:1277-85. doi:10.4271/2011-01-1336.

[32] Neubauer J, Wood E. Thru-life impacts of driver aggression, climate, cabin thermal management, and battery thermal management on battery electric vehicle utility. Journal of Power Sources 2014;259:262-75. doi:10.1016/j.jpowsour. 2014.02.083.

[33] Hosoz M, Direk M, Yigit KS, Canakci M, Turkcan A, Alptekin E, et al. Performance evaluation of an R134a automotive heat pump system for 
various heat sources in comparison with baseline heating system. Appl Therm Eng 2015;78:419-27. doi:10.1016/j.applthermaleng. 2014. 12.072 .

[34] DYMOLA Systems Engineering. Last retrieved on June 2017. URL: https://www.3ds.com/products-services/catia/products/ dymola.

[35] Air Conditioning Library, User Guide. Last retrieved on March 2017. URL: http://www.modelon.com/products/modelica-libraries/ air-conditioning-library/.

[36] Daviran S, Kasaeian A, Golzari S, Mahian O, Nasirivatan S, Wongwises S. A comparative study on the performance of HFO-1234yf and HFC134a as an alternative in automotive air conditioning systems. Appl Therm Eng 2017;110:1091-100. doi:10 .1016/j . applthermaleng . 2016 . 09.034 .

[37] Lee Y, Jung D. A brief performance comparison of R1234yf and R134a in a bench tester for automobile applications. Applied Thermal Engineering 2012;35:240-2. doi:10.1016/j . applthermaleng.2011.09.004.

[38] Span R, Wagner W. Equations of State for Technical Applications. III. Results for Polar Fluids. International Journal of Thermophysics 2003;24(1):111-62. doi:10.1023/A : 1022362231796.

[39] Servizio Meteorologico Areonautica Militare. 2014. URL: http://www . meteoam.it/.

[40] Cho H, Park C. Experimental investigation of performance and exergy analysis of automotive air conditioning systems using refrigerant R1234yf at various compressor speeds. Appl Therm Eng 2016;101:30-7. doi:10.1016/j.applthermaleng.2016.01.153.

[41] Tian Z, Qian C, Gu B, Yang L, Liu F. Electric vehicle air conditioning system performance prediction based on artificial neural network. Appl Therm Eng 2015;89:101-14. doi:10.1016/j.applthermaleng. 2015.06 .002$.

[42] SIERRA03-0982Y3 - Data Sheet. 2014. URL: http://www. masterflux.com/userimages/SIERRA03-0982Y3_Data_Sheet.pdf. 
[43] VDI Heat Atlas, Second Edition. Springer; 2010. URL: http: //elearn .univ-ouargla.dz/2013-2014/main/document/document . php?cidReq=MEPH\&action=download\&id=/livreHeatAtlas .pdf.

[44] Chang YJ, Wang CC. A generalized heat transfer correlation for louver fin geometry. International Journal of Heat and Mass Transfer 1997;40(3):533-44. doi:10.1016/0017-9310(96)00116-0.

[45] Kim NH, Cho JP. Air-side performance of louver-finned flat aluminum heat exchangers at a low velocity region. Heat and Mass Transfer 2008;44(9):1127-39. doi:10.1007/s00231-007-0346-4.

[46] Davenport CJ. Correlation for Heat Transfer and Flow Friction Characteristics of Louvered Fin. AIChE Symp Ser 1983;79:19-27.

[47] Daly S. Automotive Air-conditioning and Climate Control Systems. Amsterdam; Boston: Elsevier Butterworh-Heinemann; 2006. ISBN 9780750669559 .

[48] Woods J. Membrane processes for heating, ventilation, and air conditioning. Renewable and Sustainable Energy Reviews 2014;33:290 - 304. doi:10.1016/j.rser.2014.01.092.

[49] Zhang J, Fung AS. Experimental study and analysis of an energy recovery ventilator and the impacts of defrost cycle. Energy and Buildings 2015;87:265 -71. doi:10.1016/j.enbuild.2014.11.050.

[50] Bilodeau S. High Performance Climate Control for Alternative Fuel Vehicle. In: SAE Technical Paper. SAE International; 2001,doi:10. 4271/2001-01-1719.

[51] Alahmer A. Thermal analysis of a direct evaporative cooling system enhancement with desiccant dehumidification for vehicular air conditioning. Appl Therm Eng 2016;98:1273-85. doi:10.1016/j . applthermaleng.2015.12.059.

[52] ConsERV - Beyond fresh air. Last retrieved on March 2017. URL: http://conserv.com/engineering/.

[53] Fayazbakhsh MA, Bahrami M. Comprehensive Modeling of Vehicle Air Conditioning Loads Using Heat Balance Method. In: SAE Technical Paper. SAE International; 2013,doi:10.4271/2013-01-1507. 
[54] Ventilation for Acceptable Indoor Air Quality. Tech. Rep.; American society of Heating, Refrigeration and Air-Conditioning Engineers, inc.; 2003. URL: https://www . ashrae.org/File\%20Library/docLib/ Public/200418145036_347.pdf.

[55] UNECE Website, Worldwide harmonized Light vehicles Test Procedure (WLTP). Last retrieved on March 2017. URL: https://www2 . unece . org/wiki/pages/viewpage . action?pageId=2523179.

[56] La domanda di mobilità degli italiani. Tech. Rep.; ISFORT; 2014. URL: http://www.isfort.it/sito/statistiche/ Congiunturali/Annuali/RA_2014.pdf.

[57] Bütler T, Winkler H. Energy consumption of battery electric vehicles (BEV). Tech. Rep.; 2013. URL: http://oldweb.empa.ch/plugin/ template/empa/*/135716.

[58] Wang H, Zhang X, Ouyang M. Energy consumption of electric vehicles based on real-world driving patterns: A case study of Beijing. Appl Energy 2015;157:710-9. doi:10.1016/j . apenergy . 2015.05.057.

[59] Kelly JC, MacDonald JS, Keoleian GA. Time-dependent plug-in hybrid electric vehicle charging based on national driving patterns and demographics. Applied Energy 2012;94:395-405. doi:10.1016/j . apenergy . 2012.02 .001$.

[60] Othaganont P, Assadian F, Auger D. Sensitivity analyses for crosscoupled parameters in automotive powertrain optimization. Energies 2014;7(6):3733-47. doi:10.3390/en7063733.

[61] Mitsubishi i-Miev Specifications. Last retrieved December 2016. URL: http://www.mitsubishicars.com/imiev/specifications. 


\section{List of Figures}

1 A/C operation. In cooling mode, the system operates on a refrigeration cycle. Warm air is shown entering the ERV exchanging heat first with air flowing from the cabin and then with the refrigerant by means of internal heat exchangers. With reference to the working fluid side, red and blue arrows show respectively high temperature/high pressure and low temperature/low pressure refrigerant. . . . . . . . . . . 29

2 Heating operation. In heating mode, the system operates on a heat pump cycle. Cold air is shown entering the ERV exchanging heat first with air flowing from the cabin and then with the refrigerant by means of internal heat exchangers. With reference to the working fluid side, red arrows show high temperature/high pressure refrigerant, blue arrows indicate low temperature/low pressure refrigerant. . . . . . . . . . . . 30

3 ERV sensible and latent efficiencies as a function of air flow rate for winter and summer operating conditions. . . . . . . . 31

4 Condenser heat flux as function of air flow rate: model vs. experimental data. . . . . . . . . . . . . . . . . 32

5 Climate variables average daily trend in Rome - winter months. 33

6 Climate variables average daily trend in Rome - summer months. 34

7 Climate variables average daily trend in different Italian cities - January. . . . . . . . . . . . . . . . . . . . 35

8 Climate variables average daily trend in different Italian cities - July. . . . . . . . . . . . . . . . . . . . . . . . 36

9 Schematic of the proposed model including the thermal block, vehicle characterization and HVAC system. . . . . . . . . . 37

10 HVAC energy consumption, expressed as a percentage of traction energy, for different time of commuting and month of the year - Rome average summer days. . . . . . . . . . . . . . . . 38

11 HVAC energy consumption, expressed as a percentage of traction energy, for different time of commuting and month of the year - Rome average winter days. . . . . . . . . . . . 39

12 Compressor electric power requirements to achieve cabin comfort in July at 13:00. . . . . . . . . . . . . . . . . . . . . . . . 40

13 Comparison of HVAC energy consumption and driving range values throughout summer peak day. . . . . . . . . . . 41 
14 Energy savings (with reference to total energy required for traction and cabin air-conditioning) achievable employing an ERV-equipped HVAC system in summer. . . . . . . . . . . . . 42

15 Summer HVAC energy needs and available driving range for different Italian cities for commuting times at 8:00 (outward) and 13:00 (return). The mean value is represented with a black dot and the median with a line. . . . . . . . . . . . . 43

16 Summer HVAC energy needs and available driving range for different Italian cities for commuting times at 8:00 (outward) and 18:00 (return). . . . . . . . . . . . . . . . . 44

17 Winter HVAC energy needs and available driving range for different Italian cities for commuting times at 8:00 (outward) and 13:00 (return). . . . . . . . . . . . . . 45

18 Winter HVAC energy needs and available driving range for different Italian cities for commuting times at 8:00 (outward) and 18:00 (return). . . . . . . . . . . . . . . 46

19 Annual energy consumption for cabin thermal comfort for a basic and an ERV-equipped HVAC system. . . . . . . . . . . . 47

20 COP values for a basic and an ERV-equipped HVAC system: average values in winter months. . . . . . . . . . . . . 48 


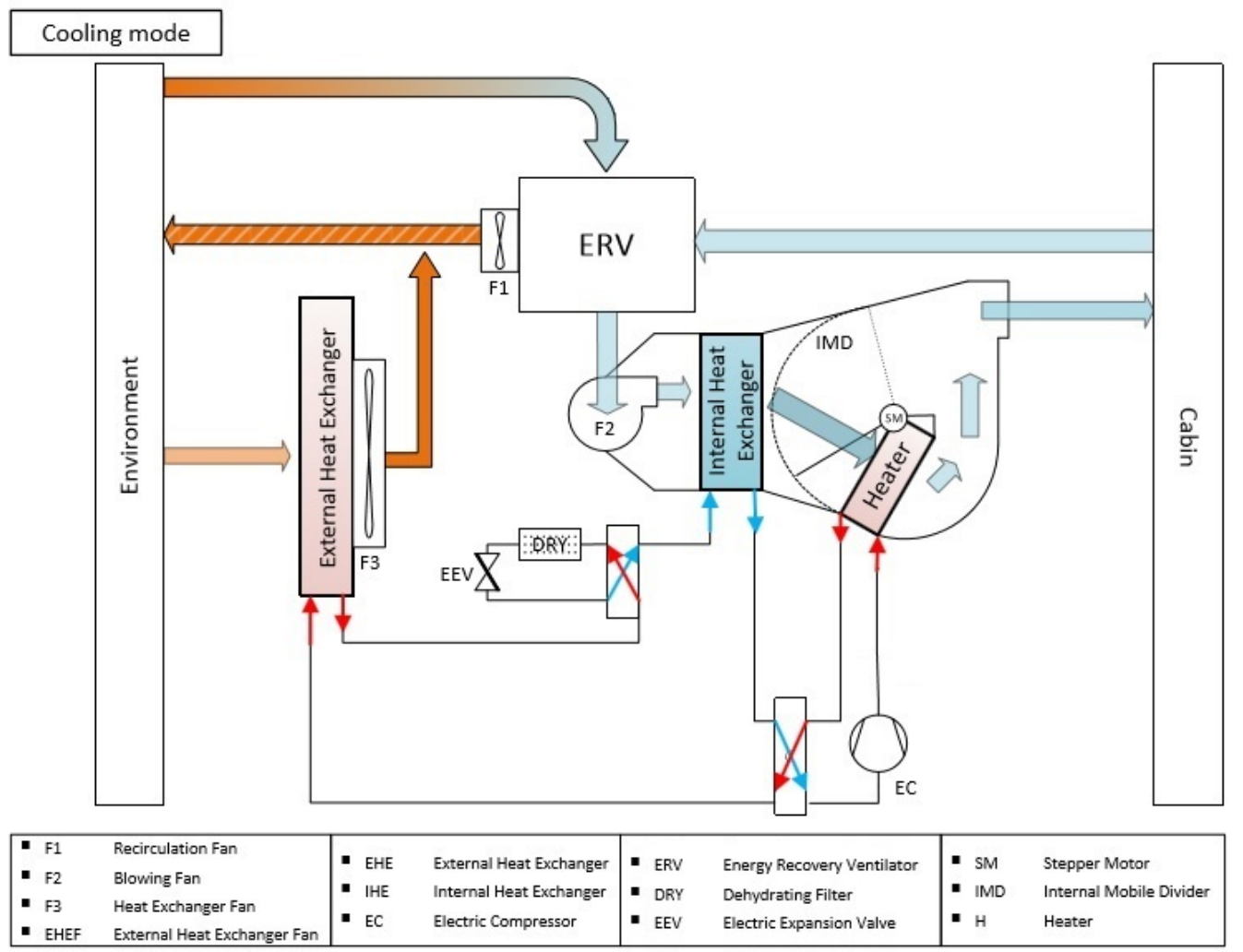

Figure 1: A/C operation. In cooling mode, the system operates on a refrigeration cycle. Warm air is shown entering the ERV exchanging heat first with air flowing from the cabin and then with the refrigerant by means of internal heat exchangers. With reference to the working fluid side, red and blue arrows show respectively high temperature/high pressure and low temperature/low pressure refrigerant. 


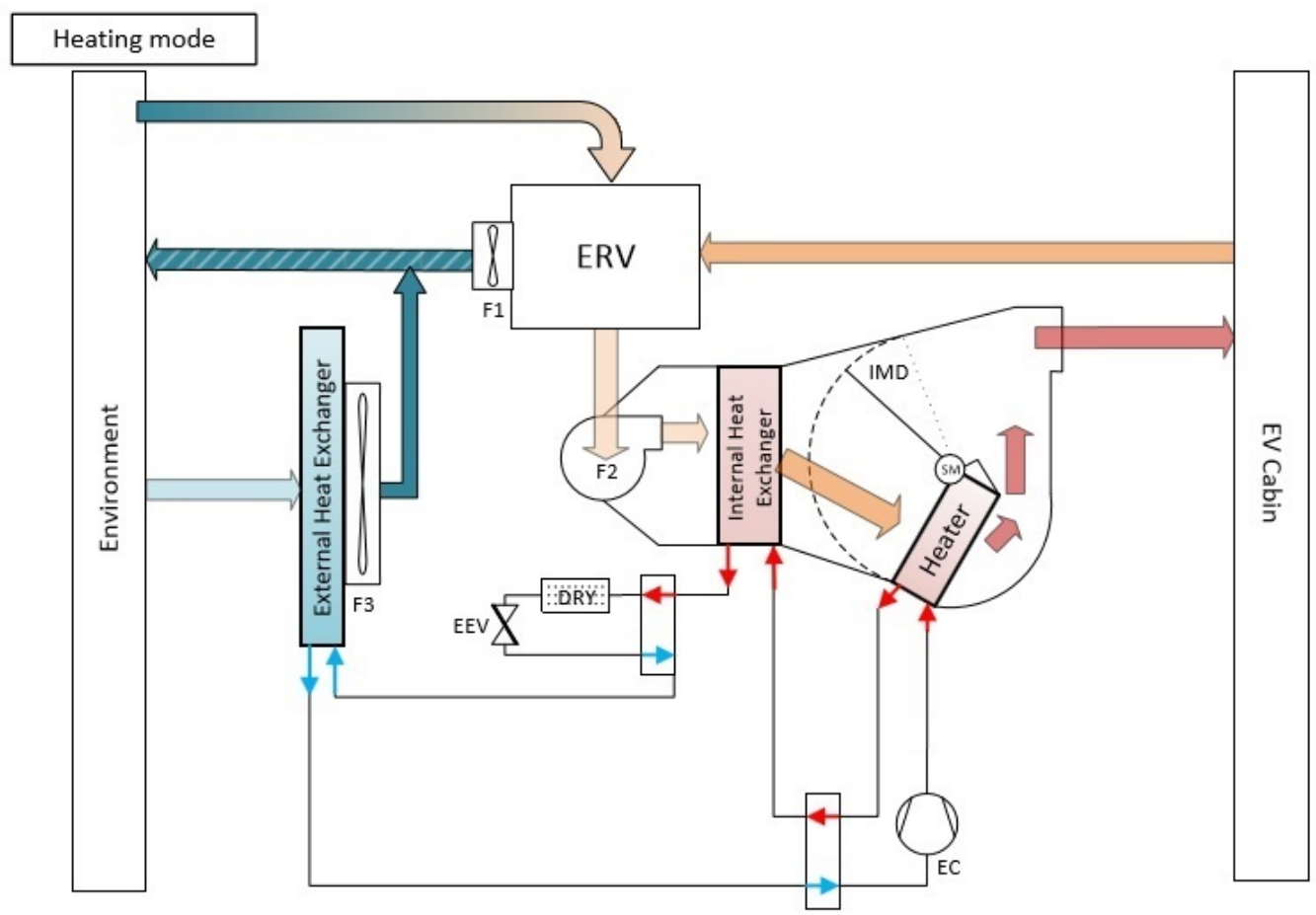

\begin{tabular}{|ll|ll|ll|ll|}
\hline - F1 & Recirculation Fan & - EHE & External Heat Exchanger & - ERV & Energy Recovery Ventilator & - SM & Stepper Motor \\
- F2 & Blowing Fan & - IHE & Internal Heat Exchanger & - DRY & Dehydrating Filter & IMD & Internal Mobile Divider \\
- F3 & Heat Exchanger Fan & - EC & Electric Compressor & - EEV & Electric Expansion Valve & - H & Heater \\
\hline - EHEF & External Heat Exchanger Fan & & & & \\
\hline
\end{tabular}

Figure 2: Heating operation. In heating mode, the system operates on a heat pump cycle. Cold air is shown entering the ERV exchanging heat first with air flowing from the cabin and then with the refrigerant by means of internal heat exchangers. With reference to the working fluid side, red arrows show high temperature/high pressure refrigerant, blue arrows indicate low temperature/low pressure refrigerant. 

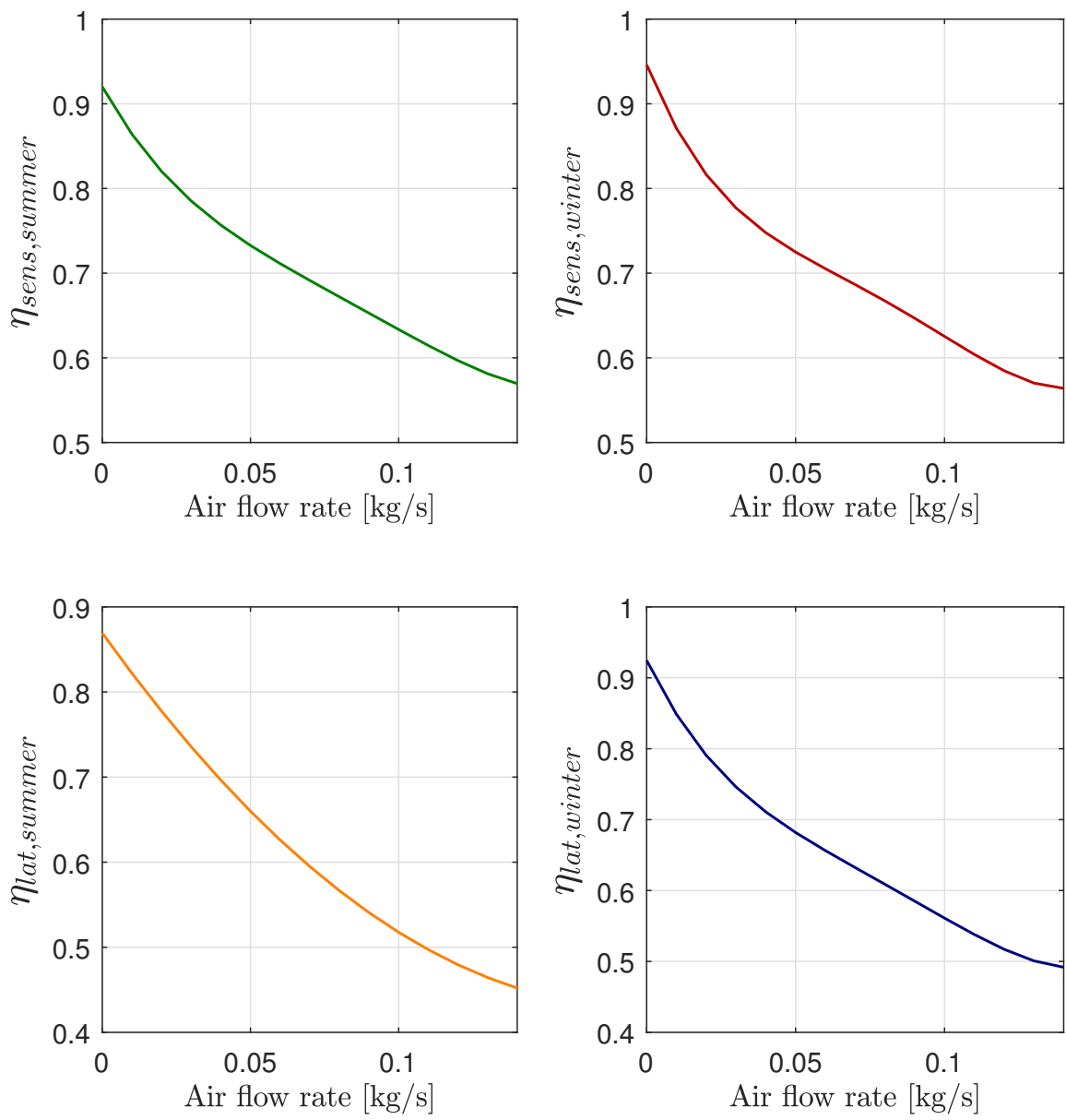

Figure 3: ERV sensible and latent efficiencies as a function of air flow rate for winter and summer operating conditions. 


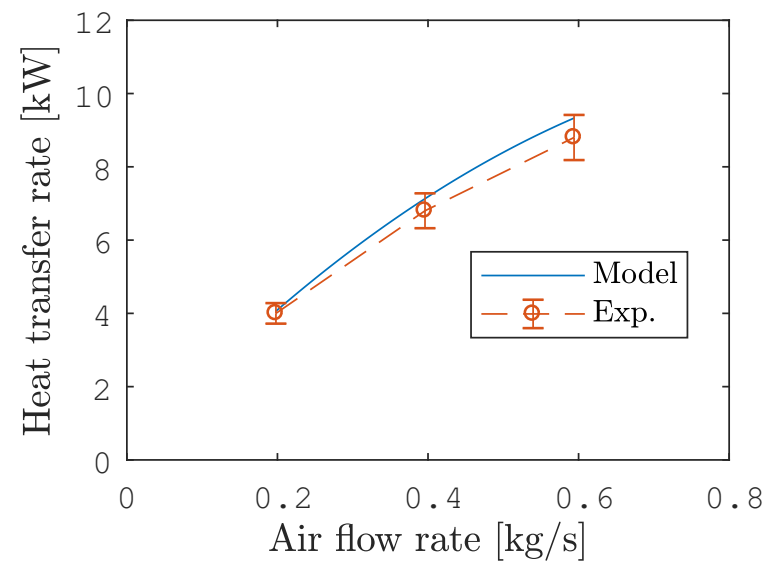

Figure 4: Condenser heat flux as function of air flow rate: model vs. experimental data. 


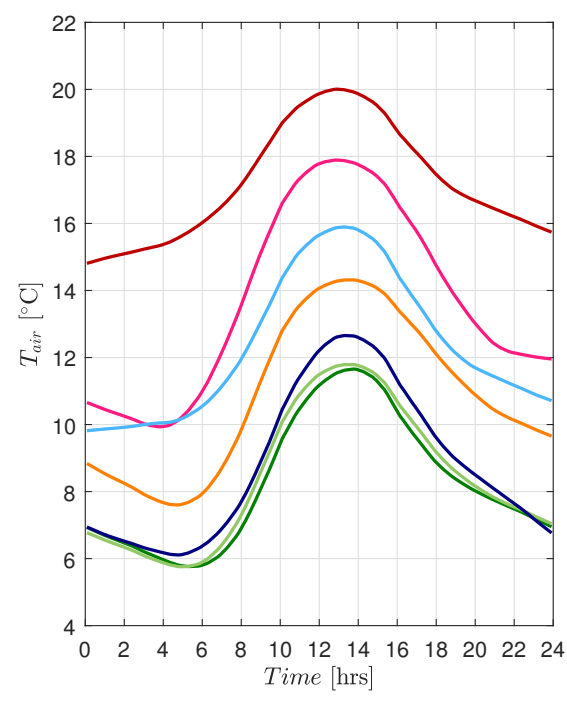

(a) Temperature

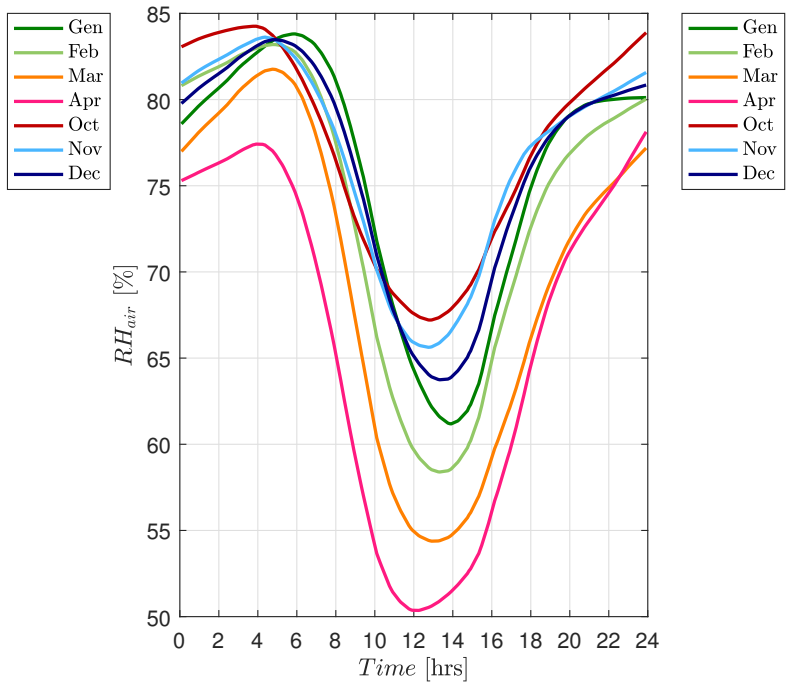

(b) Relative humidity

Figure 5: Climate variables average daily trend in Rome - winter months. 


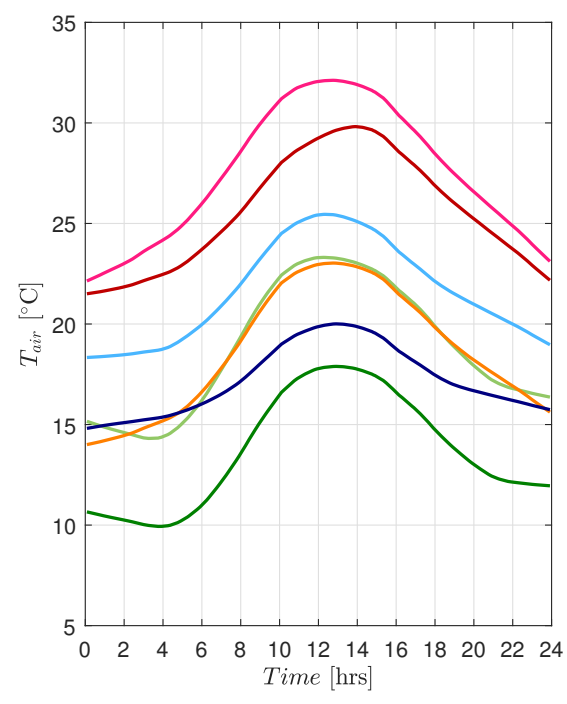

(a) Temperature

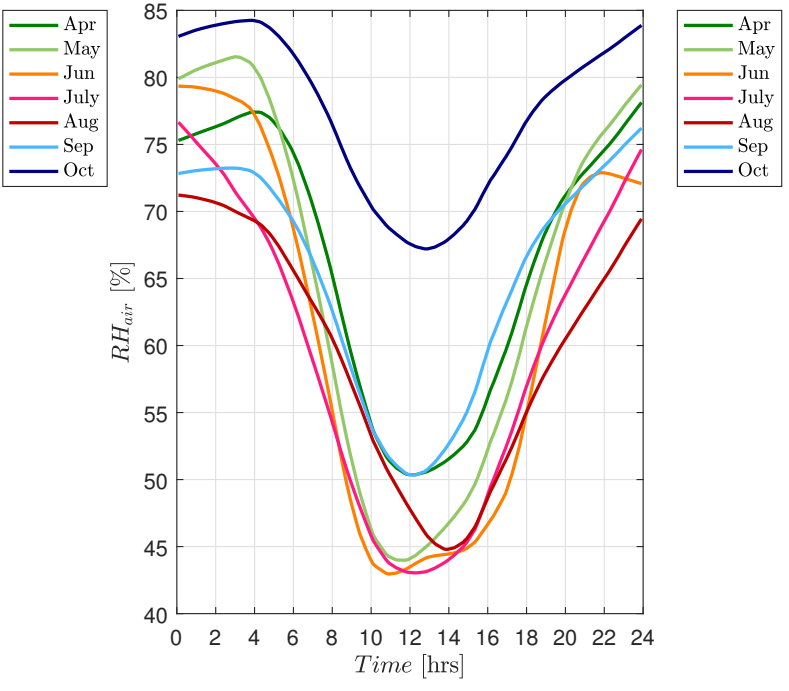

(b) Relative humidity

Figure 6: Climate variables average daily trend in Rome - summer months. 


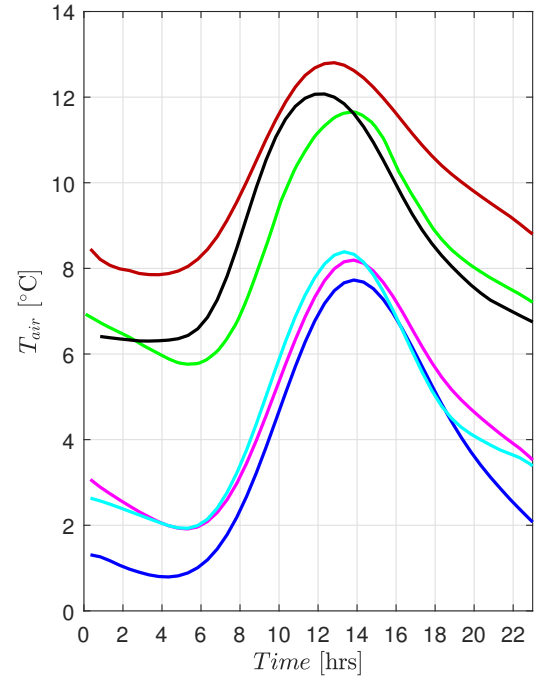

(a) Temperature
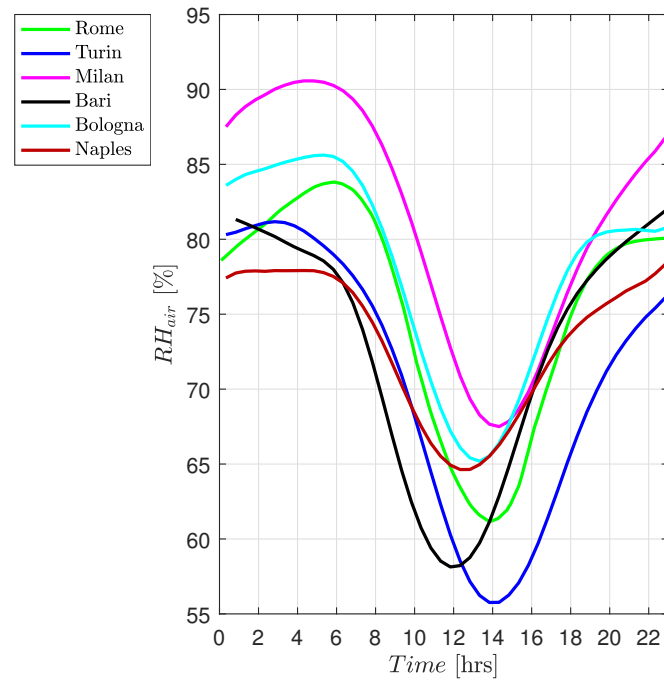

(b) Relative humidity

Figure 7: Climate variables average daily trend in different Italian cities - January. 


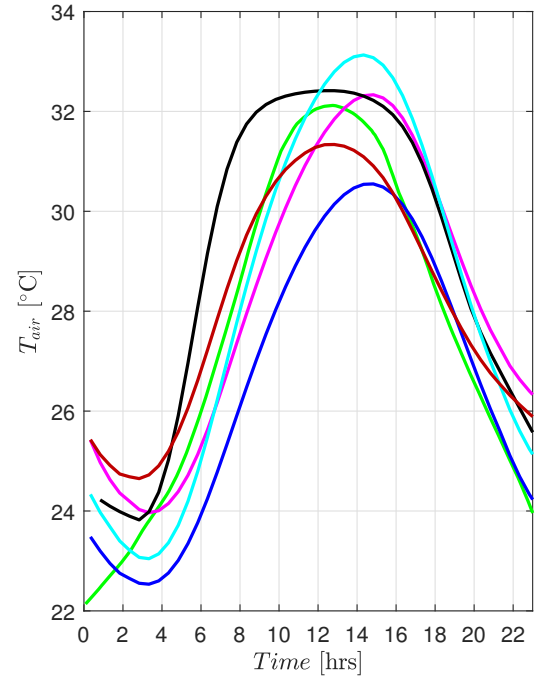

(a) Temperature
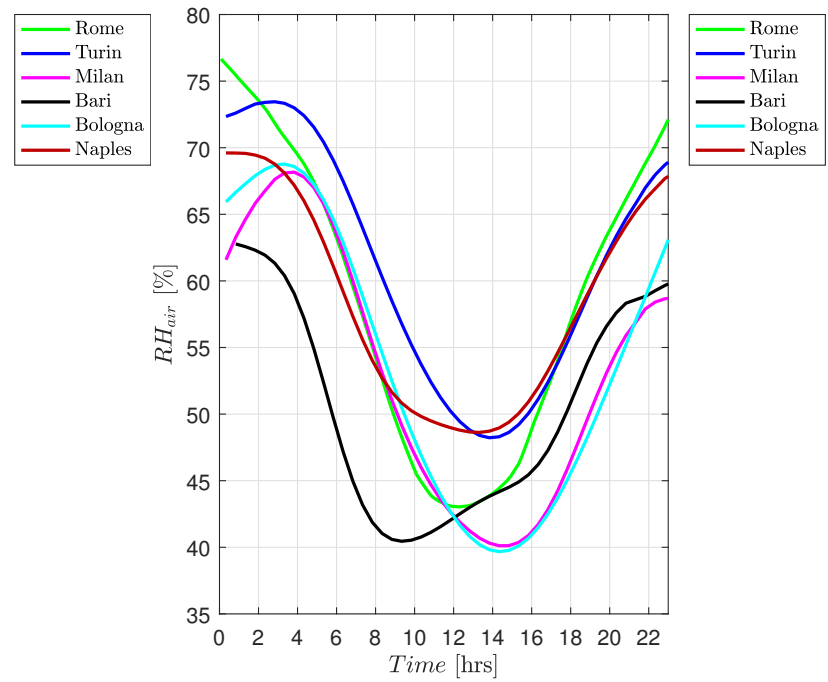

(b) Relative humidity

Figure 8: Climate variables average daily trend in different Italian cities - July. 


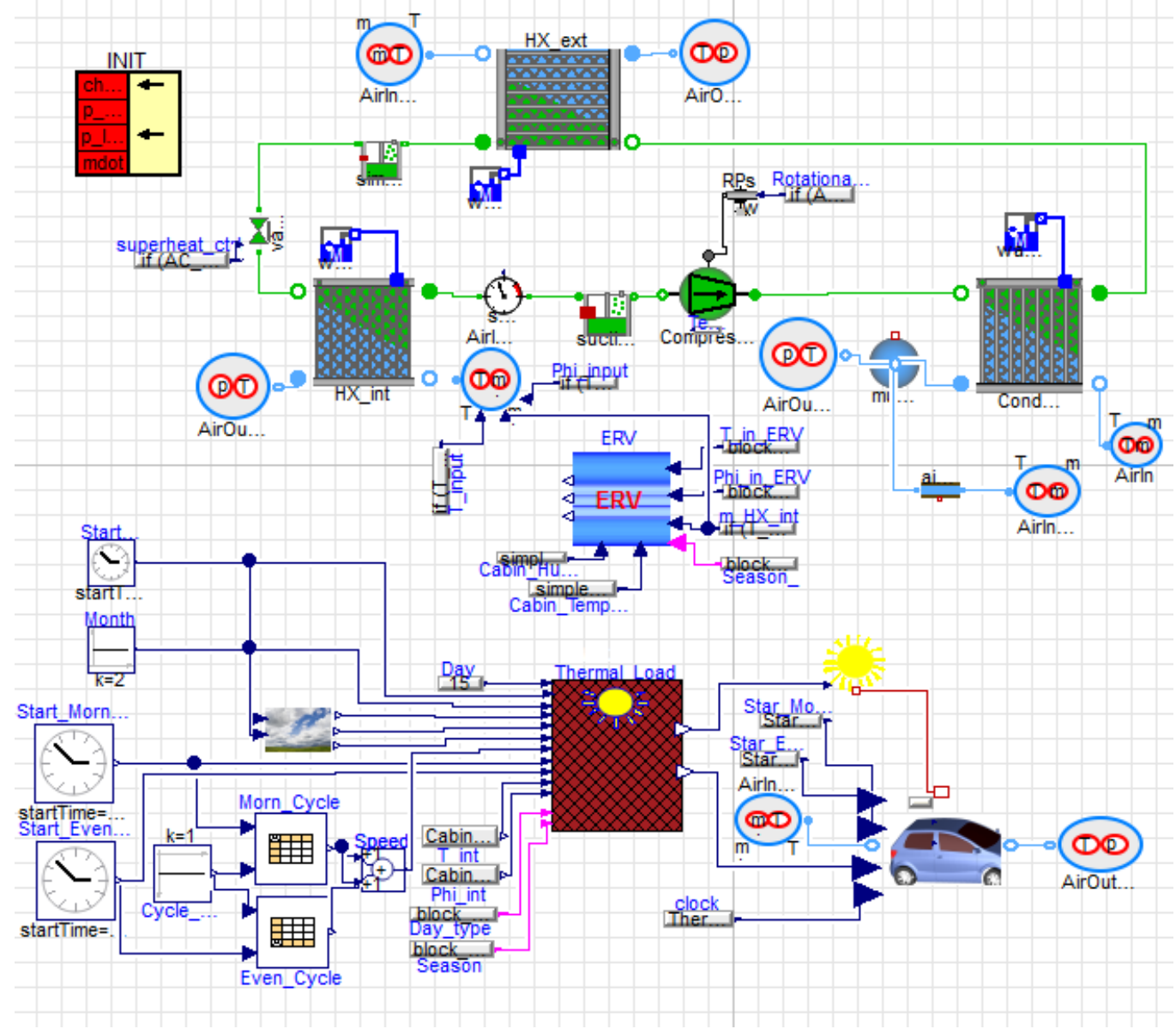

Figure 9: Schematic of the proposed model including the thermal block, vehicle characterization and HVAC system. 

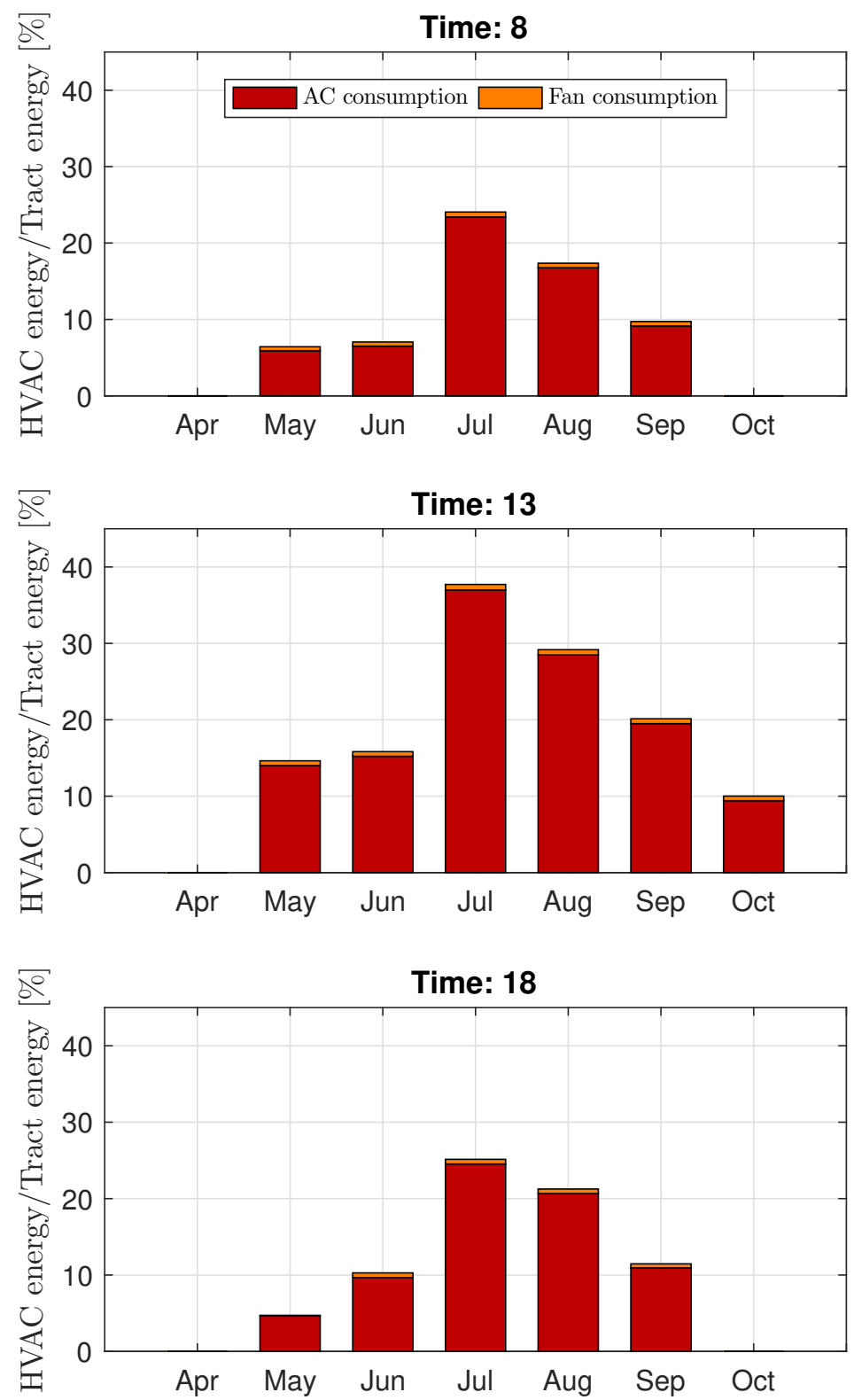

Figure 10: HVAC energy consumption, expressed as a percentage of traction energy, for different time of commuting and month of the year - Rome average summer days. 

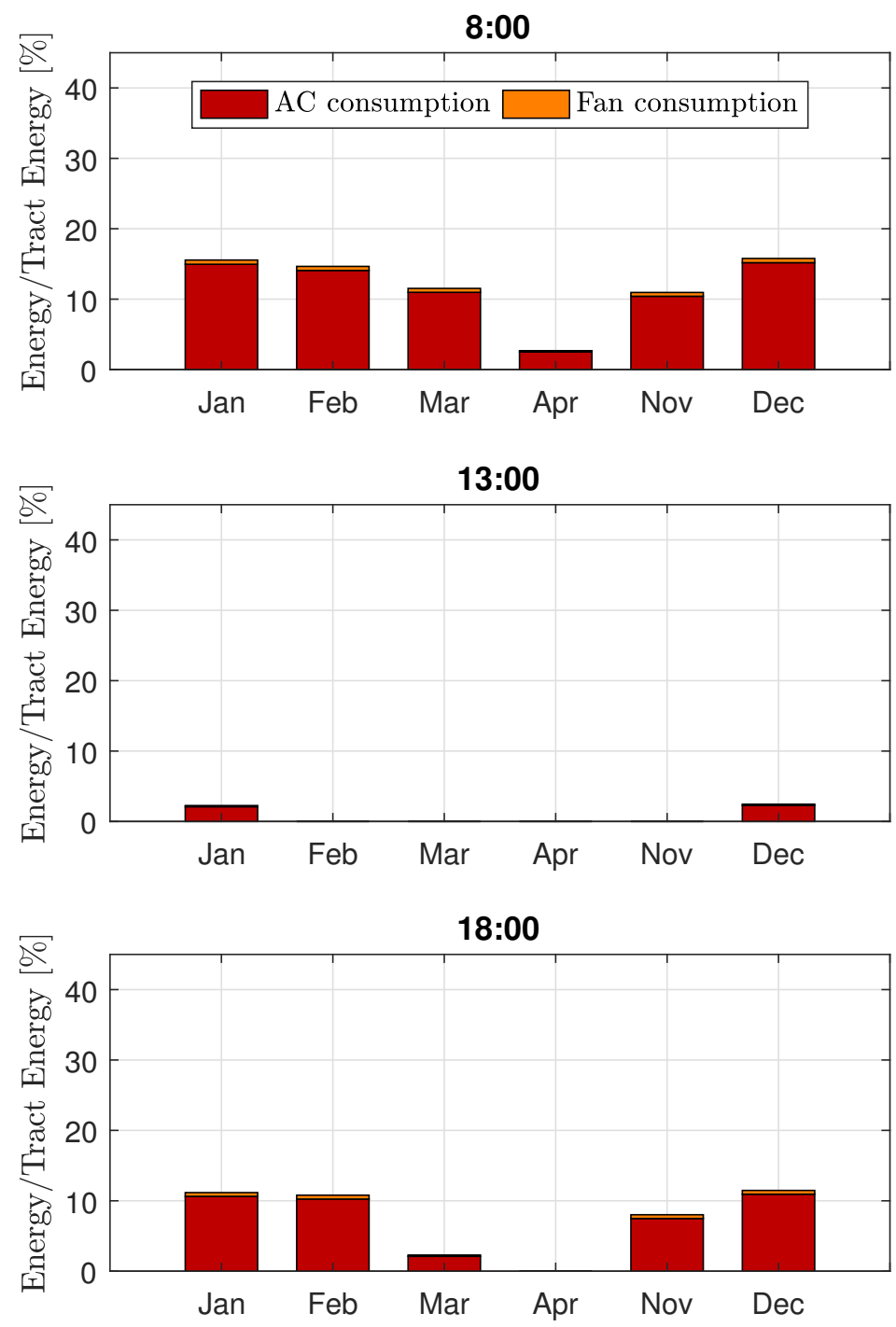

Figure 11: HVAC energy consumption, expressed as a percentage of traction energy, for different time of commuting and month of the year - Rome average winter days. 


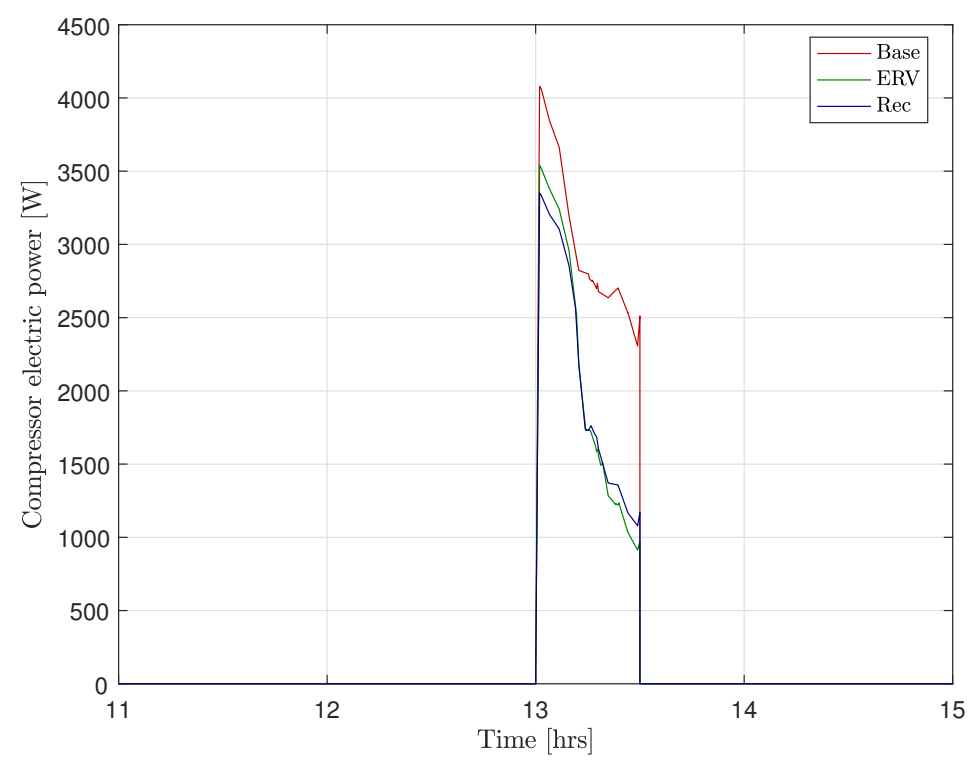

Figure 12: Compressor electric power requirements to achieve cabin comfort in July at 13:00. 

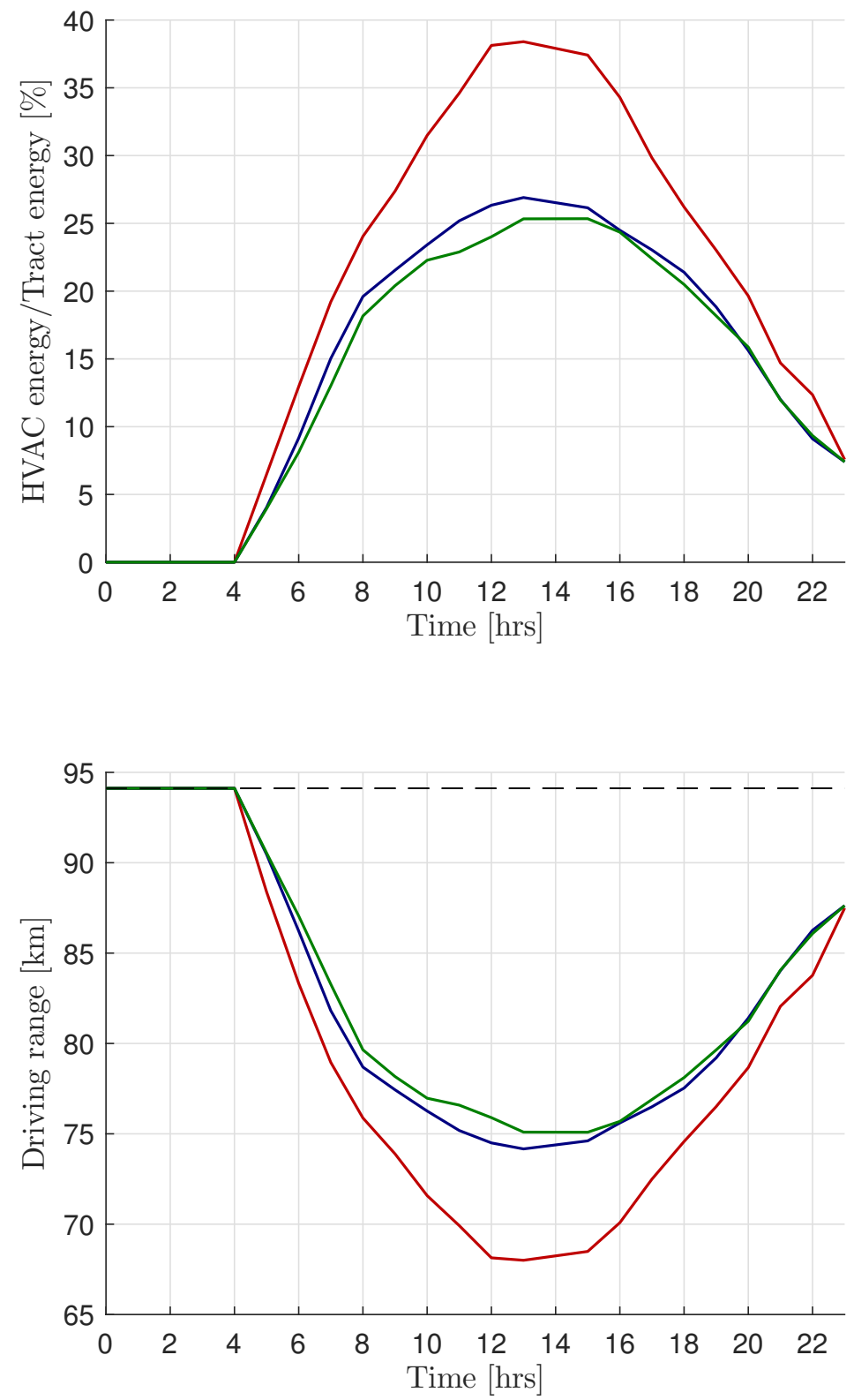

Figure 13: Comparison of HVAC energy consumption and driving range values throughout summer peak day. 

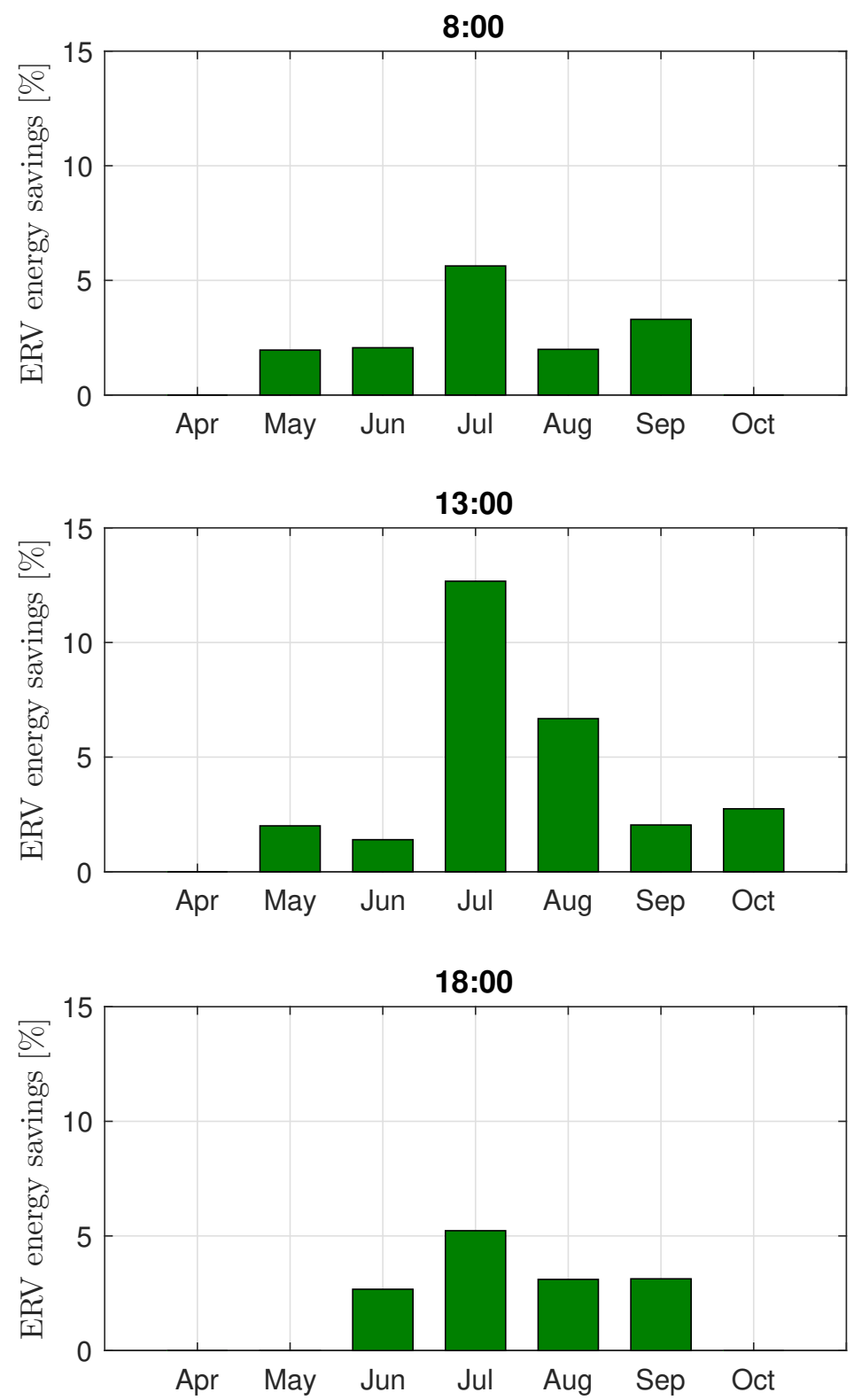

Figure 14: Energy savings (with reference to total energy required for traction and cabin air-conditioning) achievable employing an ERV-equipped HVAC system in summer. 

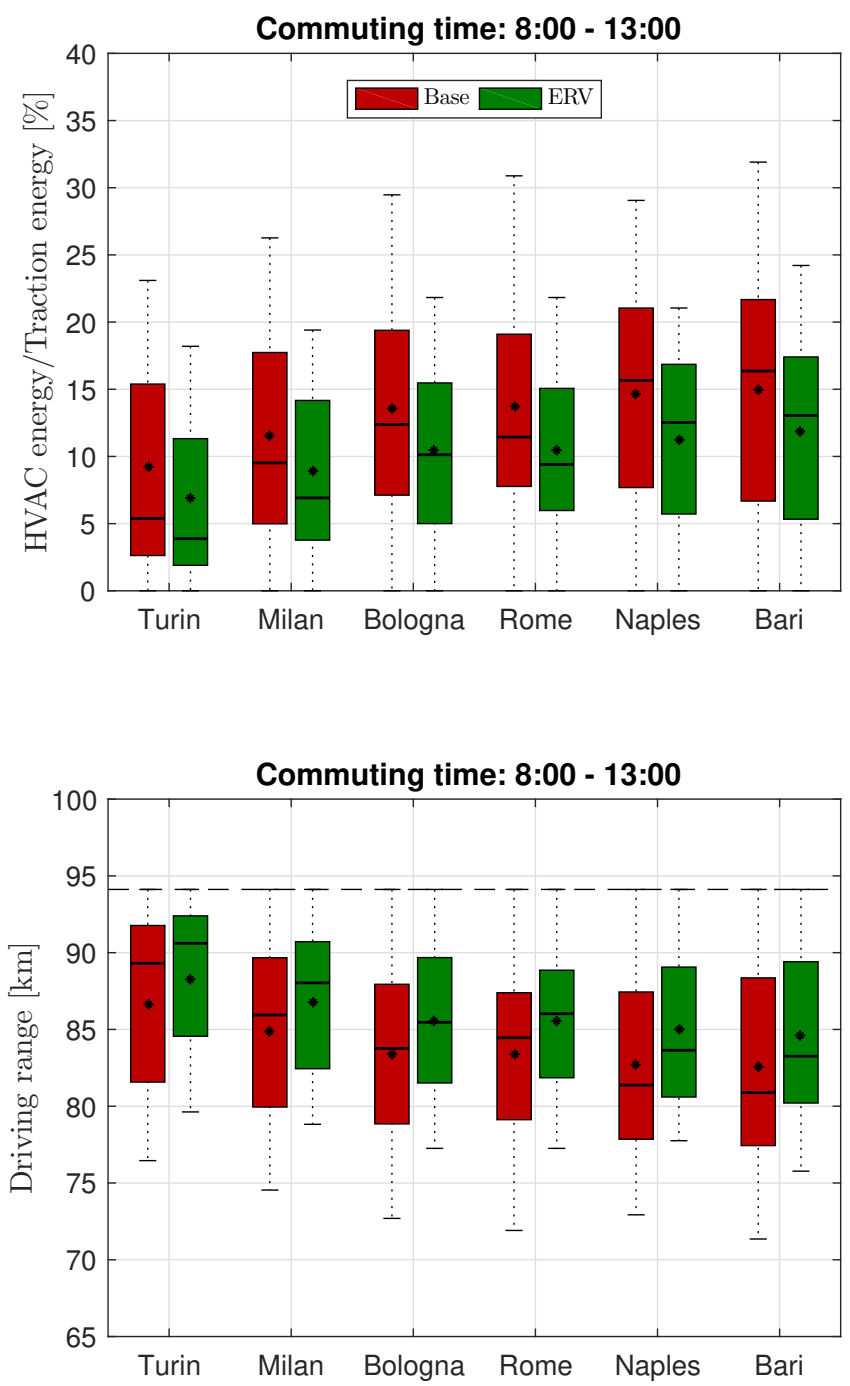

Figure 15: Summer HVAC energy needs and available driving range for different Italian cities for commuting times at 8:00 (outward) and 13:00 (return). The mean value is represented with a black dot and the median with a line. 

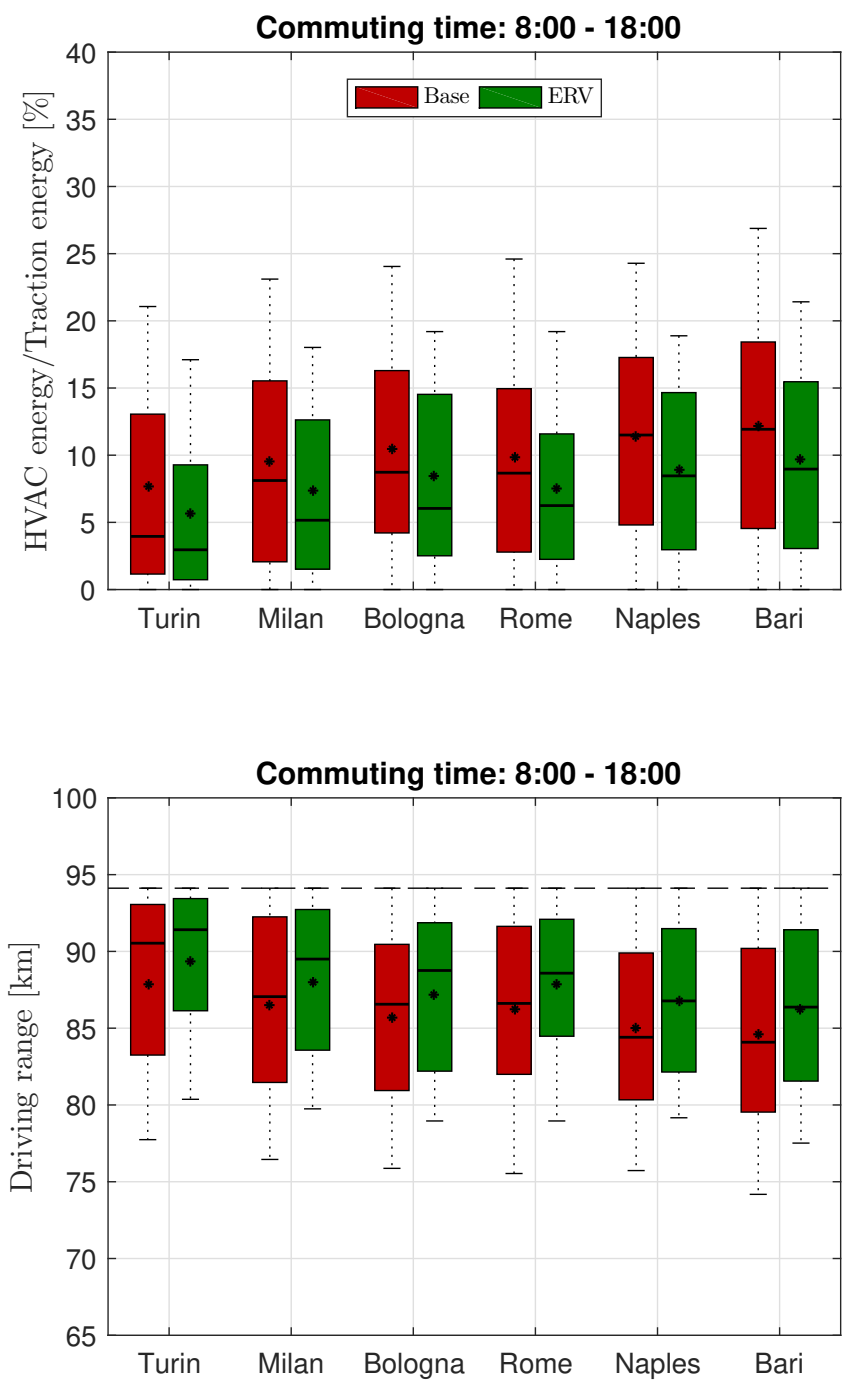

Figure 16: Summer HVAC energy needs and available driving range for different Italian cities for commuting times at 8:00 (outward) and 18:00 (return). 

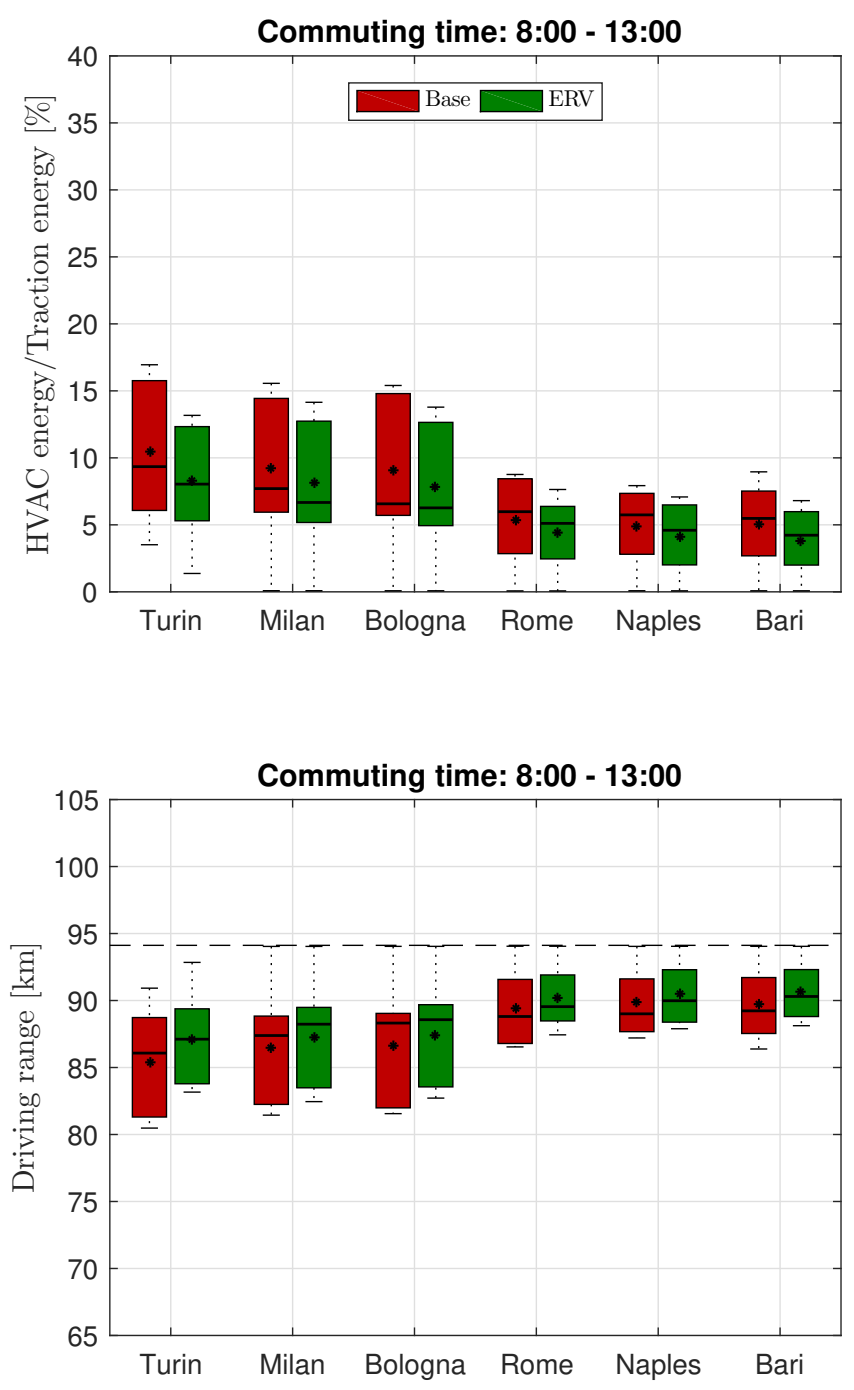

Figure 17: Winter HVAC energy needs and available driving range for different Italian cities for commuting times at 8:00 (outward) and 13:00 (return). 

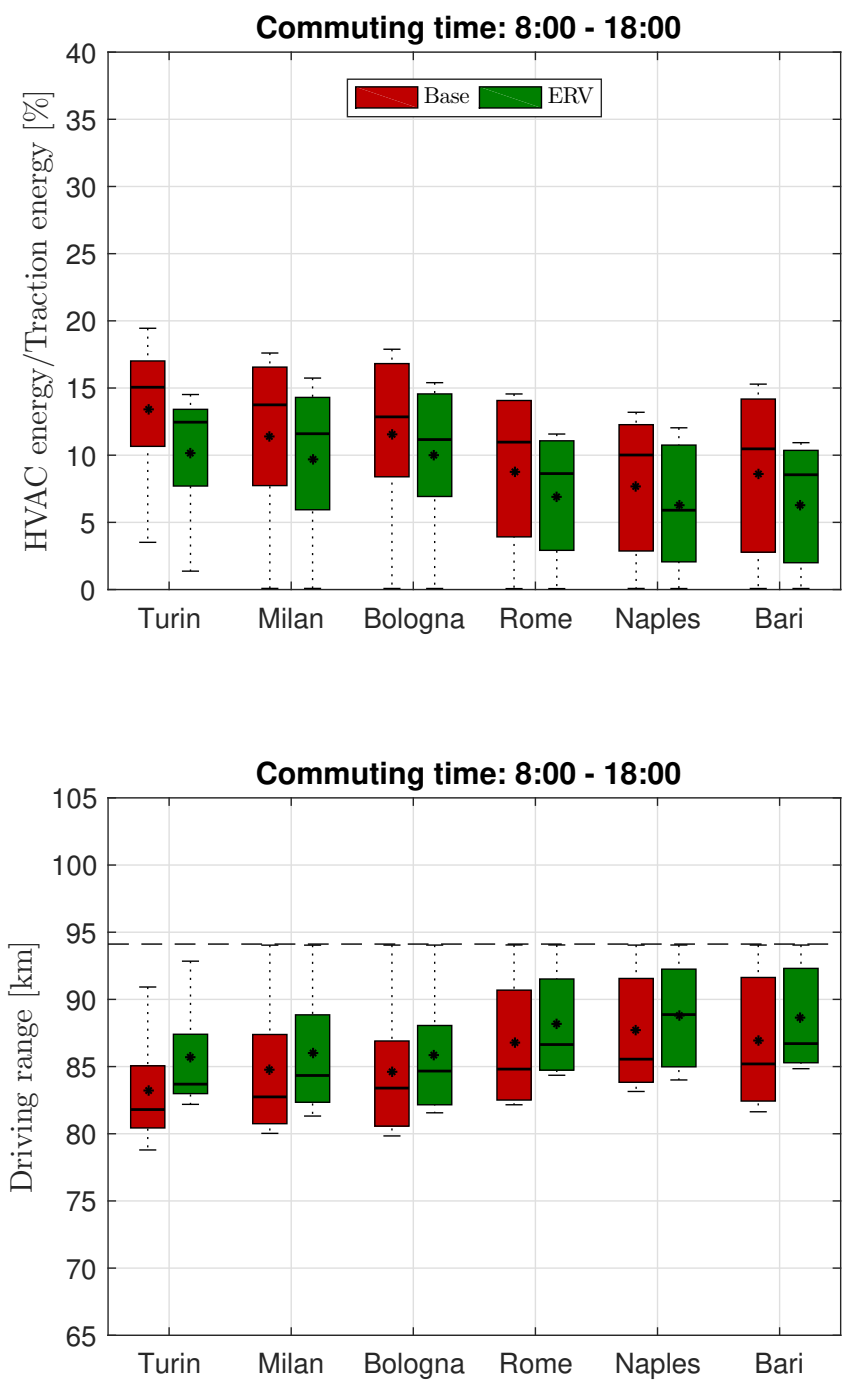

Figure 18: Winter HVAC energy needs and available driving range for different Italian cities for commuting times at 8:00 (outward) and 18:00 (return). 

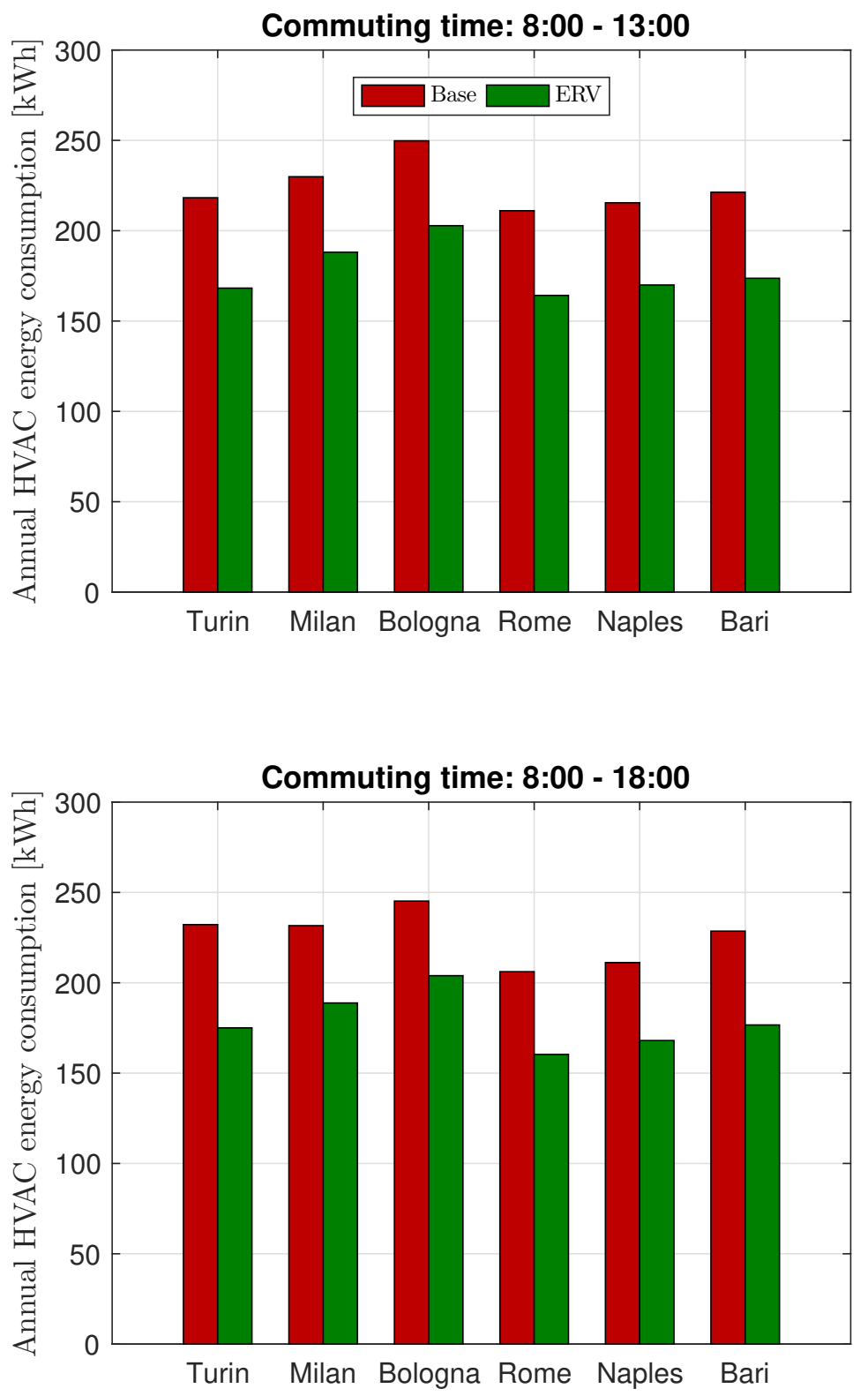

Figure 19: Annual energy consumption for cabin thermal comfort for a basic and an ERV-equipped HVAC system. 

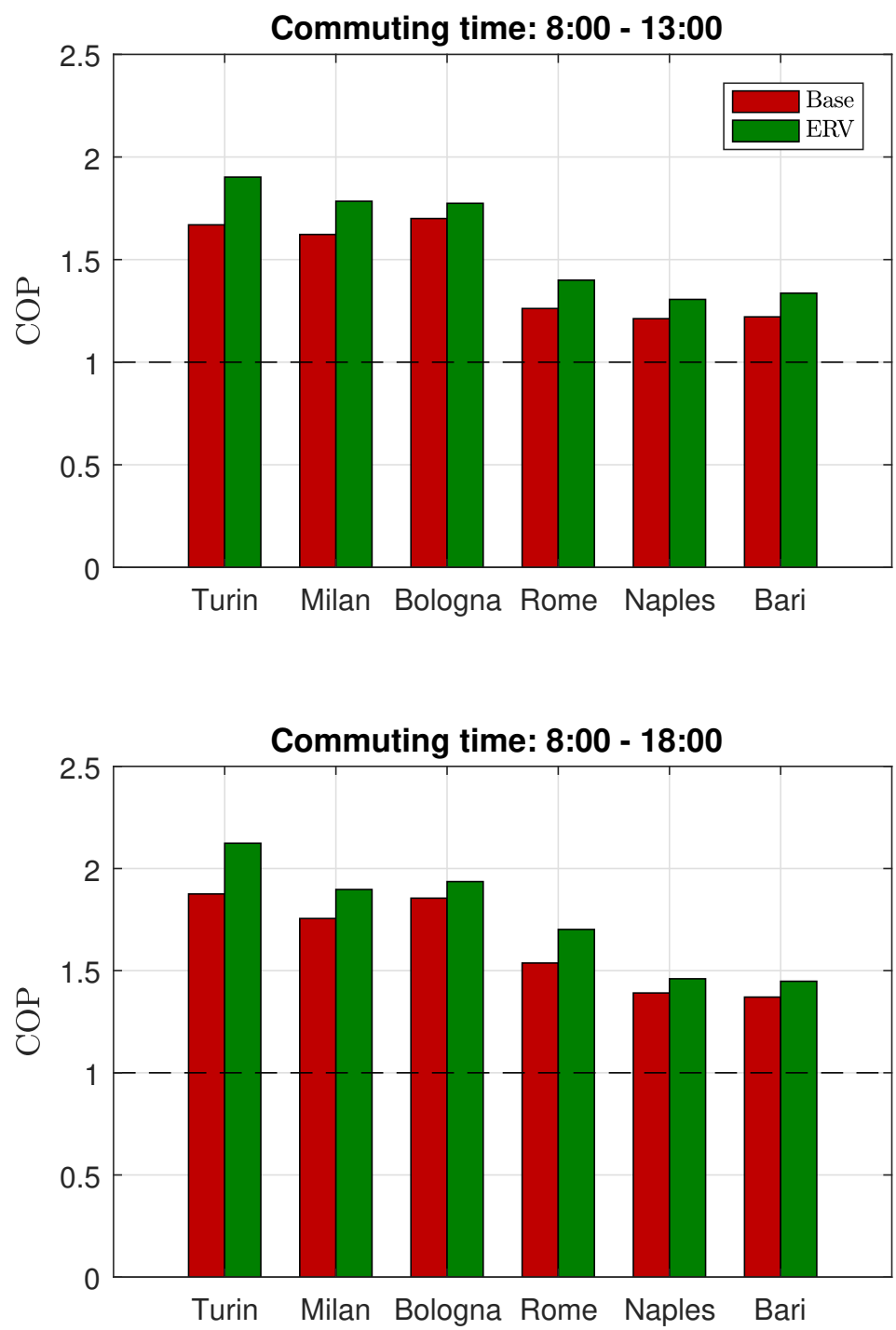

Figure 20: COP values for a basic and an ERV-equipped HVAC system: average values in winter months. 